Aus der Abteilung Palliativmedizin

(Prof. Dr. med. F. Nauck)

im Zentrum Anaesthesiologie, Rettungs- und Intensivmedizin

der Medizinischen Fakultät der Universität Göttingen

\title{
Enorale Symptome in der Palliativmedizin
}

\section{INAUGURAL-DISSERTATION}

zur Erlangung des Doktorgrades für Zahnheilkunde

der Medizinischen Fakultät der

Georg-August-Universität zu Göttingen

vorgelegt von

Ramtin KORDESTANI NEJAD

aus Teheran/Iran

Göttingen 2010 
Dekan: Prof. Dr. med. C. Frömmel

I. Berichterstatter: Prof. Dr. med. F. Nauck

II. Berichterstatter/in: Prof. Dr. med. Rödel

III. Berichterstatter/in:

Tag der mündlichen Prüfung: 16.11.2010 


\section{Inhaltsverzeichnis}

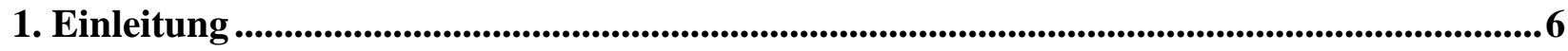

2. Fragestellungen..................................................................................................................6

3. Palliativmedizinischer Hintergrund ........................................................................................

3.1. Symptome in der Palliativmedizin .............................................................................

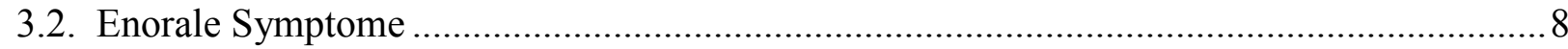

4. Untersuchung und Methode ..............................................................................................................10

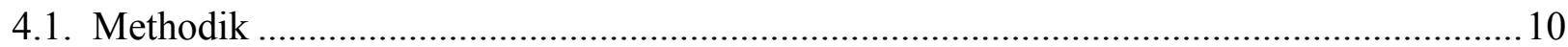

4.2. Mikrobiologische Untersuchungen an gesunden Probanden (Referenzgruppe) ..................11

4.3. Selbsteinschätzung der Symptome mittels Minimalen Dokumentationssystems MIDOS ..12

4.4. Zahnärztliche Untersuchung …………………………................................................. 13

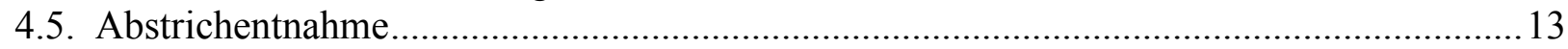

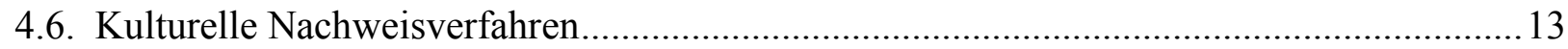

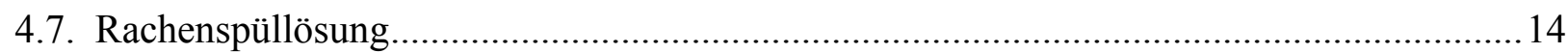

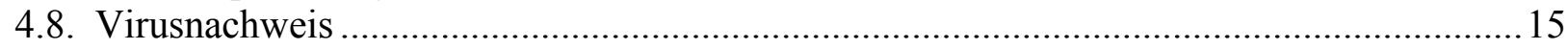

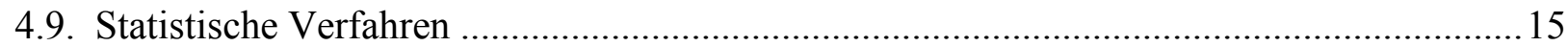

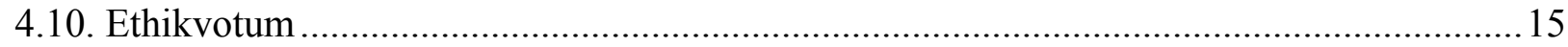

5. Ergebnisse ...........................................................................................................................................16

5.1. Altersverteilung der untersuchten Patienten.................................................................... 16

5.2. Häufigkeitsverteilung zugrundeliegender Diagnosen ..................................................... 17

5.3. Medikation und enorale Symptome ……………………………………………….....19

5.4. MIDOS: Symptome und Befinden in der Selbsteinschätzung .............................................19

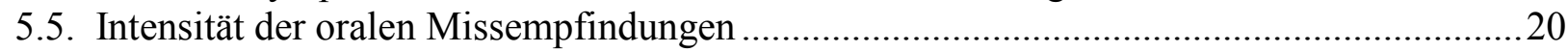

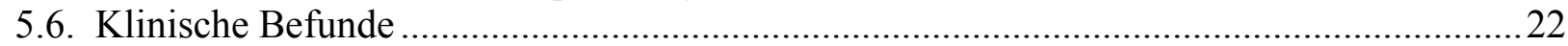

5.7. Vergleich Pilzbefunde und Beläge der Mundhöhle …………………………………........22

5.8. Chemotherapie / Radiatio und Symptomprävalenz .............................................................22

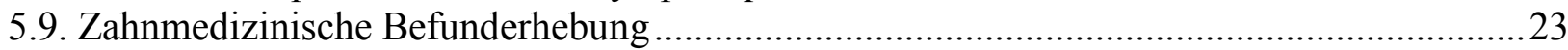

5.10. Ergebnisse mikrobiologischer Untersuchungen ..........................................................24

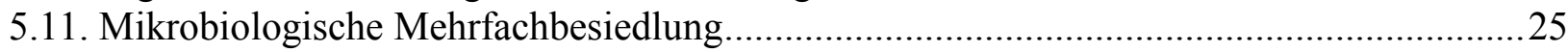

5.12. Vergleich Untersuchungsgruppe vs. Referenzgruppe ....................................................26

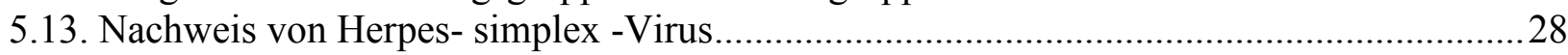

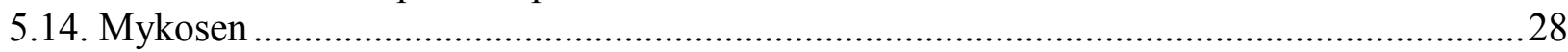

5.15. Korrelation von bakteriellen Befunden und klinischen Symptomen ..................................2 29

5.16. Zusammenhang von klinisch sichtbaren Belägen und mikrobiologischen Pilzbefunden ...32

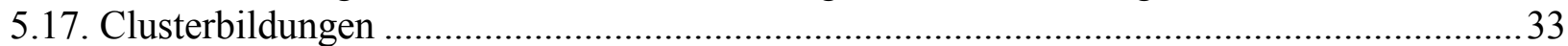

5.18. Subjektives Empfinden im Verhältnis zu klinischen und mikrobiologischen Befunden......35

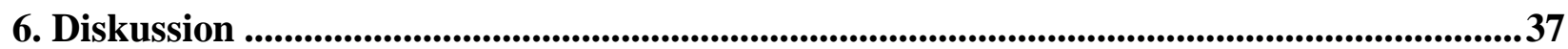

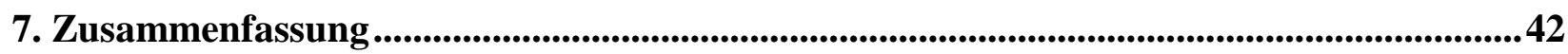

8. Literaturverzeichnis...........................................................................................................44 


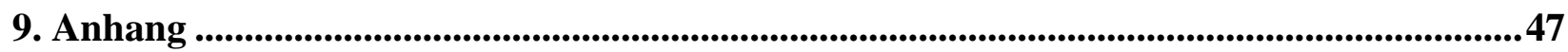

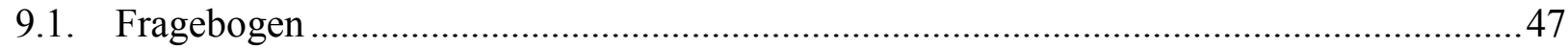

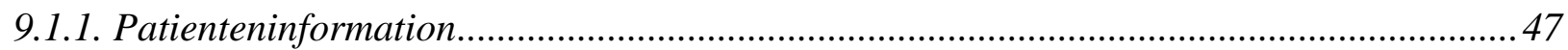

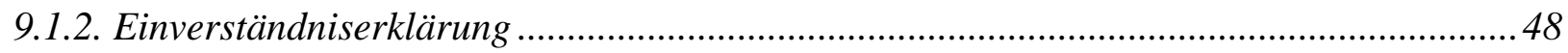

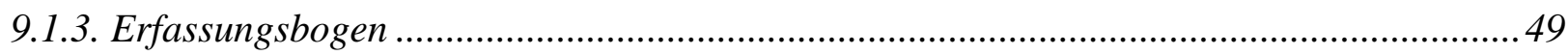

9.1.4. Minimales Dokumentationssystem MIDOS …................................................................. 53

9.2. Ausführliche statistische Auswertung der Korrelationen zu Kapitel 5.15..........................54

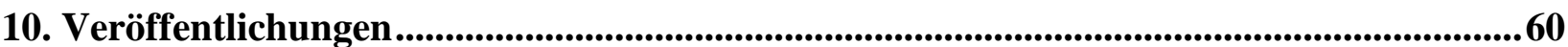




\section{Einleitung}

In Anlehnung an die Definition der WHO sind die Hauptziele der Palliativmedizin die Verbesserung der Lebensqualität und die Begleitung von Patienten mit einer nicht heilbaren, progredienten und weit fortgeschrittenen Erkrankung mit begrenzter Lebenserwartung. Die Behandlung umfasst medizinische, pflegerische, psychische, soziale und spirituelle Aspekte von Patienten und ihren Angehörigen (Saunders 1997; Husebø, Klaschik 2006).

Die palliativmedizinische Behandlungspriorität besteht darin, Lebensqualität zu verbessern und zu erhalten, insbesondere dann, wenn Maßnahmen, die auf die Verlängerung des Lebens abzielen, nicht mehr im Vordergrund stehen. Hierzu dienen neben den Maßnahmen der Symptomkontrolle auch kommunikative Techniken, psychosoziale Unterstützung sowie Kompetenzen in ethischen Fragestellungen. Entsprechend der komplexen Struktur aus somatischen und psychischen Symptomen sowie sozialen und spirituellen Bedürfnissen der Palliativpatienten ergeben sich für das therapeutische Team mannigfaltige Ansätze zur Behandlung und Intervention (Husebø, Klaschik 2006; Klaschik 1998, 2000a). Das therapeutische Team (Palliative Care Team) ist daher notwendigerweise interdisziplinär und multiprofessionell aus Ärzten, Pflegekräften, Psychologen, Seelsorgern, Sozialarbeitern und ehrenamtlichen Kräften zusammengesetzt (Klaschik 2000a).

\section{Fragestellungen}

Die vorliegende, explorative Studie untersucht, ob sich eine enorale Beschwerdesymptomatik auf eine Veränderung der normalen Mundflora oder klinisch manifeste Befunde zurückführen lässt, und inwieweit nachgewiesene klinische oder mikrobiologische Veränderungen der Mundhöhle Auswirkungen auf das Wohlbefinden des Palliativpatienten haben. Die Frage nach der Effektivität antibakterieller, antiviraler und antimykotischer Medikamente in Bezug auf die enorale Beschwerdesymptomatik wird einer Nachfolgeuntersuchung vorbehalten sein.

Im Einzelnen sollten folgende Fragen beantwortet werden:

1) Welche enoralen Beschwerden werden bei Patienten auf der Palliativstation der Universitätsklinik Göttingen mit welcher Häufigkeit angegeben?

2) Welche Vorbehandlungen (antibakterieller, antiviraler, antimykotischer, tumorspezifischer Art) sind vorausgegangen? 
3) Weicht die Mundflora von Palliativpatienten ab von der „normalen“ physiologischen Mundflora? Sind Palliativpatienten mit einer physiologischen Mundflora diesbezüglich asymptomatisch?

4) Welche pathogenen Keime finden sich?

5) Inwieweit korrelieren spezifische enorale Symptome mit Abweichungen von der normalen Mundflora bzw. dem Nachweis pathogener Keime im Mund-Rachen-Raum?

\section{Palliativmedizinischer Hintergrund}

\subsection{Symptome in der Palliativmedizin}

\section{Schmerz}

In der Palliativmedizin werden Patienten mit vergleichsweise komplexen Problemen behandelt. Viele Patienten werden einige Wochen oder Monate in anderen Fachdisziplinen behandelt, bevor sie auf die Palliativstation verlegt werden. Schmerzen zählen hierbei zu den häufigsten und dringlichsten behandlungsbedürftigen Symptomen (Twycross 1994, Bonica et al. 1990, Klaschik 1998, Radbruch et al. 2003).

\section{Dyspnoe}

Dyspnoe ist das subjektive Symptom der Atemnot, dessen Schwere vor allem in der Selbsteinschätzung des Patienten zum Tragen kommt. Die Perzeption des Symptoms Dyspnoe wird dabei dual bestimmt von der Wahrnehmung der Atemnot selbst und zum anderen von der Reaktion der Patienten auf Atemnot (Comroe et al. 1968; Husebø, Klaschik 2006).

\section{Übelkeit und Erbrechen}

Übelkeit und Erbrechen ist bei einer Inzidenz von 40-70\% ein häufiges Symptom bei Patienten mit fortgeschrittener Tumorerkrankung. Der Schweregrad dieses Symptoms hängt stark von der Progredienz des Tumors, der Begleiterkrankungen des Patienten sowie begleitenden therapeutischen Maßnahmen ab.

\section{Obstipation}

Obstipation ist ein weiterer häufig anzutreffender klinischer Befund bei Palliativpatienten, der mit einer zu niedrigen Stuhlfrequenz, zu geringen Stuhlmenge, zu harter Stuhlkonsistenz und einer als zu schwierig empfundenen Stuhlentleerung einher geht (Müller-Lissner 1992). 


\section{Intestinale Obstruktion}

Symptome einer intestinalen Obstruktion umfassen unter anderem ein aufgetriebenes Abdomen, Nausea, Emesis, kolikartige oder kontinuierliche Abdominalschmerzen und Stuhlverhalt.

\subsection{Enorale Symptome}

Neben den oben genannten klassischen Symptomen wie Schmerzen, Atemnot und gastrointestinalen Problemen nehmen enorale Symptome wie Schmerzen der Mundhöhle, Geschmacksstörungen (Dysgeusie) und Mundtrockenheit (Xerostomie) ebenfalls einen Stellenwert in der symptomorientierten palliativmedizinischen Behandlung ein; in der Einschätzung durch das Palliativteam wird dieser Symptomkomplex jedoch als eher hintergründig wahrgenommen (Radbruch et al. 2003).

\section{Mundtrockenheit (Xerostomie)}

Einhergehend mit verringertem Speichelflusses können an fast allen Geweben der Mundhöhle Veränderungen auftreten. Leichte Fälle von Mundtrockenheit verlaufen relativ symptomlos, ohne wesentliche Auswirkungen auf den klinischen Befund. In ausgeprägten Situationen ist das Bild der Mundtrockenheit jedoch gekennzeichnet durch eine trockene, blasse, glatte und klebrig-glänzende Mundschleimhaut, während es an der Zunge zunehmend zu einer Atrophie der Papillen und zu Fissurenbildungen kommt (Langlais und Miller 1994). In schweren Fällen können Schmerzen der Zunge (Glossodynie) sowie Schmerzen und Schwellungen der Speicheldrüsen auftreten (Haneke 1980).

\section{Zahnschmerzen}

Zahnschmerzen können durch die unterschiedlichsten Faktoren verursacht werden. Karies, schlechte Mundhygiene, freiliegende Zahnhälse, Paradontopathien, Schleimhautirritationen, Mukositiden, oder mechanische Irritationen in Form von Prothesendruckstellen oder schlecht sitzende Prothesen sind nur einige der zugrundeliegenden Faktoren.

\section{Mundgeruch (Halithosis)}

Die Lebensqualität der Betreffenden kann durch Mundgeruch empfindlich gestört werden. Im Krankenhaus, Alten- / Pflegeheimen kann Mundgeruch die Pflegesituation durch ein 
denkbares Vermeidungsverhalten seitens der Pflegenden belasten (Fidler et al. 1996; Lang, Filippi 2005; www.zungenhygiene.de). Aber auch in der Gesellschaft wird Mundgeruch weitgehend tabuisiert und mit negativen Reaktionen besetzt.

\section{Unspezifisches Brennen (Burning-mouth-syndrom / BMS)}

Zungen und Schleimhautbrennen treten entweder als Begleiterscheinung einer allgemeinen Erkrankung oder als eigenständige Erkrankung auf. Die Prävalenz ist hoch. Die Betroffenen klagen oft über Missempfinden, die als brennender Schmerz, wundes Gefühl und als Kribbeln oder Jucken wahrgenommen werden. Die Symptome nehmen im Lauf der Zeit zu, und chronifizieren schließlich. Bei den Patienten handelt es sich fast immer um Prothesenträger (Al-Zahrany et al. 2003).

\section{Dysgeusie}

Geschmacksstörungen können unterteilt werden in:

- $\quad$ verminderte Geschmackswahrnehmung (Hypogeusie)

- völlig fehlende Geschmackswahrnehmung (Ageusie)

- $\quad$ veränderte Geschmackswahrnehmung (Dysgeusie).

Die oben genannten Störungen können einzeln (Ageusie bei allen Lebensmitteln) oder kombiniert (Hypogeusie bei einzelnen Lebensmitteln und Dysgeusie bei anderen Lebensmitteln) auftreten. Patienten geben unterschiedliche Geschmacksempfindungen an, zum Beispiel, dass Mahlzeiten als salzig oder geschmacksneutral empfunden werden (Ripamonti und Fulfaro2005; Vetter 2005).

\section{Schluckbeschwerden (Dysphagie)}

Dysphagische Schluckbeschwerden weisen eine große Variabilität auf, von leichten Mißempfindungen hin zu ausgeprägten Beschwerden mit der Unfähigkeit jeglicher Nahrungsoder Flüssigkeitsaufnahme. Das Schlucken und Kauen kann zudem aufgrund von Mukositiden und fehlendem Speichel erschwert sein.

Bezüglich dieser Symptome, ihrer Verteilung, ihrer Intensität und ihrer zugrunde liegenden Ursachen gibt es bislang sehr wenige wissenschaftliche Untersuchungen. Im bisherigen Fokus stehen dabei Untersuchungen zu Chemo- und Strahlentherapie-induzierter oraler Mucositis und Xerostomie (Saadeh 2005; Sweeney et al. 1997) bei onkologischen Patienten. Bei den wenigen Untersuchungen an Palliativpatienten werden rein symptomorientierte Maßnahmen und primär infektiologische Konzepte vorgestellt und diskutiert (Bagg et al. 2003; Sweeney, Bagg 2000); eine klare Assoziation zwischen subjektiv empfundenen lokalen Symptomen und einer 
dazugehörigen Veränderung der normalen Mundflora, einer pathologischen Keimbesiedelung oder klinischen Befunden steht jedoch aus.

\section{Untersuchung und Methode}

\subsection{Methodik}

Im Rahmen einer prospektiven Studie mit Pilot-Charakter wurden in Zusammenarbeit mit der Abteilung Mund-, Kiefer- und Gesichtschirurgie (Prof. Dr. Dr. Schliephake), der Abteilung Mikrobiologie (Prof. Dr. Groß, Prof. Dr. Eiffert) und der Abteilung Virologie (Prof. Dr. Hunsmann) der Universität Göttingen auf folgende Weise die im Sinne der Fragestellung relevanten Informationen generiert:

- Vom 1. Januar 2008 an wurden konsekutiv 101 Patienten der Palliativstation der Universitätsklinik Göttingen nach vorheriger schriftlicher Patienteninformation und Aufklärung (Anhang) in Bezug auf ihr Allgemeinbefinden, in Bezug auf Symptome der Mundhöhle und bezüglich ihrer Krankheitsvorgeschichte befragt und mit Hilfe eines strukturierten und vom Untersucher entwickelten Anamnese- und Befunderhebungsbogens dokumentiert (Anhang)

- Die Patienten schätzten ihre aktuelle Symptomlast mit Hilfe des Minimalen Dokumentationssystems MIDOS ein (Anhang; Radbruch et al.2000)

- Anamnestische Daten wurden ergänzt durch Informationen aus der Patientenakte

- Im Rahmen der klinischen Aufnahmeuntersuchung erfolgte eine ca. fünf Minuten dauernde zahnärztliche Erhebung des Zahnstatus und des Parodontalstatus (Anhang), gefolgt von einem Wattetupferabstrich der Mundschleimhaut und einer Mundspülung mit Aqua dest.

- Der Watteabstrich wurde in die Abteilung Mikrobiologie der Universität Göttingen zur semiquantitativen bakteriologischen und mykologischen Untersuchung verschickt und dort analysiert; das Rachenspülwasser wurde in der Abteilung Virologie der Universität Göttingen auf Herpes-simplex-Viren mittels PCR quantitativ untersucht.

- Im Falle pathologischer Befunde wurden diese im Rahmen des palliativmedizinischen Therapieansatzes in einer Kooperationsabsprache mit der Abteilung Mund-, Kieferund Gesichtschirurgie kurzfristig mitbehandelt, so dass die zahnärztliche Kurzbefunderhebung dem Patienten unmittelbar zugute kam. 
Der Untersucher und Doktorand ist approbierter und praktizierender Zahnarzt und qualifiziert daher für eine professionelle klinische Befunderhebung und symptom- und bedarfsorientierte Mitbehandlung. Subjektive Symptome, klinische Befunde, Abweichungen von der normalen Mundflora und anamnestische Rahmenbedingungen wurden miteinander korreliert.

Patientenbezogene Daten wurden mit Hilfe eines Zahlencodes pseudonymisiert, so dass intern ggfs. eine Plausibilitätsprüfung mit Hilfe der Patientenakte erfolgen konnte, nach extern jedoch ein ausreichender Grad an Datensicherheit resultierte. Konsultationen des zuständigen Datenschutzbeauftragten aufgrund von Unklarheiten waren nicht erforderlich. Die Untersuchungen fanden meist an den Samstagen der Woche zwischen 9:30 Uhr und 12:30 Uhr statt. Diese Zeit schien aufgrund des Stationsablaufes und aufgrund der Patienten, Angehörigen und Besucher am besten geeignet. Die Auswahl der Patienten fand in Beratung mit den behandelnden Stationsärzten sowie dem Pflegepersonal statt, wobei Ansprechbarkeit, Kognition und Kooperation entscheidende Auswahlkriterien darstellten, dies auch vor dem Hintergrund der Zumutbarkeit in Bezug auf die kurze Untersuchung. Vor jeder Untersuchung wurden die Patienten über die Art und Dauer der Untersuchung sowie der Ziele der Studie informiert und aufgeklärt. Die Patienten unterschrieben vor der Untersuchung die Einverständniserklärung (Anhang) und wurden informiert, dass zu jeder Zeit die Möglichkeit bestand, die Untersuchung abzubrechen bzw. die Teilnahme zu verweigern, ohne dass Nachteile zur befürchten wären.

\subsection{Mikrobiologische Untersuchungen an gesunden Probanden (Referenzgruppe)}

Im Rahmen der Literaturrecherche im Hinblick auf die Keimbesiedlung der Mundhöhle wurden einige vorangegangene Untersuchungen (Lehmann 1991; Andrä und Naumann 1971; Hellwege 1984; Keller 1994; Kayser 1993; Mombelli 1994) und eine interne Studie herangezogen. Das Institut für Medizinische Mikrobiologie der Universität Göttingen untersuchte 1997 insgesamt 100 gesunde Probanden hinsichtlich ihrer Mundflora. Diese Ergebnisse wurden uns kollegialerweise im Sinne einer nicht abgestimmten Kontrollgruppe zur internen Referenz zur Verfügung gestellt. Es wurden bei 100 gesunden Probanden (Mitarbeiter der Abteilung und Studenten) Abstriche der Mundschleimhaut entnommen und mikrobiologisch untersucht (Tabelle 1). Bei 51 Personen kam mindestens ein in der Mundflora quantitativ oder qualitativ auffälliger Keim vor. In fünf Fällen wurden zwei abweichende Keime nachgewiesen, bei 
einem Probanden drei von der physiologischen Mundflora abweichende Keime. Insgesamt wurde bei 37 Probanden eine Besiedlung mit Hefepilzen nachgewiesen.

\begin{tabular}{|c|c|c|c|c|}
\hline Von der physiologischen Norm abweichende Keimbesiedlung & gesamt: & reichlich & mäßig & vereinzelt \\
\hline Streptococcus viridans & 11 & 11 & & \\
\hline Escherichia coli & 5 & 2 & & 3 \\
\hline Klebsiella pneumoniae & 5 & 1 & & 4 \\
\hline Enterococcus faecalis & 5 & & & 5 \\
\hline Neisseria species & 4 & & & 4 \\
\hline Staphylococcus aureus & 3 & & & 3 \\
\hline Koag. neg. Staphylokokken & 6 & & & 6 \\
\hline Pseudomonas aeruginosa & 1 & & & \\
\hline Moraxella catarrhalis & 4 & & 1 & 3 \\
\hline Streptococcus pneumoniae & 3 & & & \\
\hline Serratia marcescens & 1 & & 1 & \\
\hline Streptococcus der Gruppe A & 3 & & 1 & \\
\hline
\end{tabular}

Tabelle 1: Mikrobiologische Befunde bei gesunden Probanden (interne Daten Abt. Mikrobiologie,

Universitätsmedizin Göttingen)

\subsection{Selbsteinschätzung der Symptome mittels Minimalen Dokumentationssystems MIDOS}

Im Rahmen der durchgeführten Studie wurde der MIDOS-Bogen (Anhang) ebenfalls als ein Teil der Erfassung des Allgemeinbefindens der Patienten eingesetzt.

Beim MIDOS Patientenfragebogen zur Selbsterfassung von Schmerzen werden für die durchschnittliche Schmerzstärke und die stärksten Schmerzen jeweils eine numerische Rating-Skala von 0 (= kein Schmerz) bis 10 (= stärkster vorstellbarer Schmerz) angeboten. Für die körperlichen Symptome und ein psychisches Symptom Angst werden vier Antwortkategorien mit „keine“, „leichte“, „mittlere“ bis „starke“ angeboten. Die Patienten haben die Möglichkeit, für zwei weitere von ihnen ergänzte Begriffe eine Intensität anzugeben. Eine Frage nach dem Befinden bietet fünf Antwortkategorien zweipolig an, von „sehr schlecht“ bis „sehr gut“. Weitere Bemerkungen können eingetragen werden. In Situationen, in denen eine Selbsterfassung nicht möglich ist, sollen die Gründe wie Sprachprobleme, Schwäche, kognitive Störungen, Ablehnung durch den Patienten, aber auch „keine Zeit"“ angegeben werden. 


\subsection{Zahnärztliche Untersuchung}

Bei der zahnärztlichen Untersuchung der Patienten wurde in Anbetracht der kurzen Untersuchungsdauer die Anzahl der Zähne, Art des Zahnersatzes, DMF-T-Index sowie eine Visuelle Beurteilung der Mundhygiene ohne Plaqueanfärbung durchgeführt (Tabelle 14).

Mundhygiene der Patienten ist in den jeweiligen Altersgruppen mit "gut", "mittel" und "schlecht" bewertet worden.

Der DMF-T-Index $(\mathrm{D}=$ diseased $=$ erkrankt; $\mathrm{M}=$ missing $=$ fehlend $; \mathrm{F}=$ filled $=$ mit einer Füllung versehen und $\mathrm{T}=$ tooth / teeth) ist ein statistischer Gradmesser für die Schwere bzw. Auswirkung einer Karieserkrankung und dient zur Dokumentation der Ausprägung des Kariesbefalls bei einer Person und der Prävalenz in einer Untersuchungsgruppe.

Bei dieser Erfassung werden Weisheitszähne und überkronte Zähne ebenfalls als erkrankt angegeben.

\subsection{Abstrichentnahme}

Zur Abstrichentnahme wurde das Abstrichbesteck Transystem ${ }^{\circledR}$ der Firma Hain verwendet. Es handelt sich hierbei um einen Universal-Abstrichtupfer mit einem sog. AmiesTransportmedium. Der Abstrich wurde mit dem sterilen Watteträger im Bereich der bukkalen Mundschleimhaut, des Rachenringes sowie der Zunge durchgeführt. Die Abstriche wurden zum Erregernachweis von Bakterien und Pilzen dem Institut für Medizinische Mikrobiologie der Universität Göttingen zugeführt.

\subsection{Kulturelle Nachweisverfahren}

Zur Identifizierung und dem Nachweis von Pilzen und Bakterien, wurden diese zunächst auf festen oder flüssigen Nährmedien als Primärkultur zur Vermehrung gebracht. Anschließend fand die Isolation und Identifikation der Erreger in Reinkultur statt. Nährmedien zur in-vitro-Kultivierung waren:

- McConkey-Agar zur Kultivierung von Enterobakterien

- Kochblutagar (Basismedium) zur Kultivierung von Streptokokken, Neisserien etc.

- Mannit-Kochsalz-Agar zur Kultivierung von Enterokokken 
Die Beimpften Kochblutplatten als auch Selektivmedien wurden in einem Brutschrank (luftdicht unter $\mathrm{CO}_{2}$-Atmosphäre und $37^{\circ} \mathrm{C}$ ) für $24 \mathrm{Std}$. inkubiert.

Anhand der makroskopischen Betrachtung der Kulturen wurde die Kolonienmorphologie beurteilt.

Wachstumsmuster:

- Streptokokken auf Kochblutagar : kleine konvexe Kolonien, nicht pigmentiert

- Staphylokokken: flache Kolonien, graugelblich pigmentiert

- Enterokokken: konvexe Kolonien, graue und glasig/schleimig.

Durch ein standardisiertes Testverfahren (bioMérieux Deutschland GmbH), wurde die biochemische Differenzierung durchgeführt. Die Identifizierung der Erregerkulturen erfolgte nach Standardprotokollen.

Das Bakterienwachstum wird wie folgt angegeben:

"+": geringes Wachstum,

“++“: mäßiges Wachstum,

“+++“: reichliches Wachstum.

Eine weitere Einordnung der Bakterien wurde aufgrund Ihrer Gramfärbung durchgeführt und entsprechend der Empfindlichkeit des jeweiligen Erregers wurde ein Antibiogramm erstellt.

\subsection{Rachenspüllösung}

Zur Gewinnung der Rachenspüllösung wurde den Patienten nach der Abstrichentnahme eine definierte Menge von Aqua dest. $(10 \mathrm{ml})$ in einem sterilen Becher zum Spülen angereicht. Die Patienten sollten die Lösung so lange wie möglich in der Mundhöhle behalten und falls möglich spülen und gurgeln, bevor die Spüllösung wieder in den Becher zurückgeben wurde. Diese Lösung wurde ebenfalls dem Institut für Mikrobiologie der Universität Göttingen zum Nachweis von HS-Viren übersandt. 


\subsection{Virusnachweis}

Zum Virusnachweis wurden PCR-basierte Methoden eingesetzt $(\mathrm{PCR}=$ polymerase chain reaction). Die Methode der Polymerasekettenreaktion nutzt das Enzym DNA-Polymerase, um DNA in vitro zu vervielfältigen. Der Begriff "Kettenreaktion" beschreibt in diesem Zusammenhang die Tatsache, dass die Produkte vorheriger Zyklen als Ausgangsstoffe für den nächsten Zyklus dienen und somit eine exponentielle Vervielfältigung ermöglichen.

\subsection{Statistische Verfahren}

Eine erste biometrische und methodologische Beratung fand bei Herrn Prof. Dr. Hilgers, Abt. Medizinische Statistik der Universität Göttingen, 10/2007 statt.

Die Rohdaten wurden mithilfe einer Microsoft Access Datenbank gesammelt und mit Mitteln der deskriptiven und analytischen Statistik ausgewertet. Mittelwerte und prozentuale Anteile wurden errechnet. Der explorative Charakter der Studie steht einer multiplen Signifikanzberechnung post hoc entgegen (Regel nach Bonferoni). Insofern müssen die hier mit Hilfe des Chi-Quadrat-Vierfelder-Tests bestimmte Signifikanzen (festgelegt als $\mathrm{p}<0,05$ ) eher als relevante Korrelationen interpretiert werden, die einer prospektiven Validierung bedürfen.

Die Unabhängigkeit einzelner Variablen wurde mittels logarithmischer Regressionsanalyse berechnet.

\subsection{Ethikvotum}

Die Studie wurde von der Ethikkommission der Medizinischen Fakultät Göttingen in der Sitzung vom 27.05.2008 zustimmend bewertet. 


\section{Ergebnisse}

Im achtmonatigen Studienzeitraum 2008 wurden 171 Patienten auf der Palliativstation der Universitätsmedizin Göttingen behandelt. Nach klinischen Kriterien (siehe Kapitel 4.1. Methodik) wurden 106 Patienten bezüglich einer Teilnahme in der Studie angefragt. Fünf Patienten lehnten eine Studienteilnahme ab, so dass 101 Patienten eingeschlossen werden konnten.

\subsection{Altersverteilung der untersuchten Patienten}

Im Untersuchungszeitraum von März bis November 2008 wurden insgesamt 101 Patienten untersucht (davon 60 Frauen und 41 Männer) [Tabelle 2].

Die Patientengruppe im Alter zwischen 60-80 Jahren ist mit insgesamt 48,5\% $=49$ Personen (davon 20 Männer und 29 Frauen) am stärksten vertreten, gefolgt von der Gruppe im Alter zwischen 40-60 (34,6\%). Innerhalb dieser Gruppe sind Frauen mit 22 und Männer mit 13 Personen unterschiedlich vertreten (Abbildung 1, 2).

Auf die Gruppe der über 80-Jährigen entfielen 12 Patienten (davon sieben Männer und fünf Frauen). Eine Minderzahl (ein Mann und drei Frauen) waren der Gruppe der 30-40-Jährigen zuzuordnen. Die jüngste untersuchte Person war eine 27 jährige Patientin und die älteste ein 95 Jähriger Patient.

\begin{tabular}{|c|c|c|c|c|c|c|c|c|c|c|c|c|c|c|}
\hline \multirow[t]{2}{*}{ Alter } & \multicolumn{2}{|r|}{$<30$} & \multicolumn{2}{|c|}{$30-40$} & \multicolumn{2}{|c|}{$40-50$} & \multicolumn{2}{|r|}{$50-60$} & \multicolumn{2}{|c|}{$60-70$} & \multicolumn{2}{|c|}{$70-80$} & \multicolumn{2}{|c|}{$>80$} \\
\hline & $\mathrm{n}$ & $\%$ & & $\%$ & & $\%$ & & $\%$ & & $\%$ & & $\%$ & & $\%$ \\
\hline Gesamt & 1 & 100 & 4 & 100 & 19 & 100 & 16 & 100 & 25 & 100 & 24 & 100 & 12 & 100 \\
\hline Männlich & 0 & 0 & 1 & 25 & 6 & 31,6 & 7 & 43,8 & 11 & 44 & 9 & 37,5 & 7 & 58,4 \\
\hline Weiblich & 1 & 100 & 3 & 75 & 13 & 68,4 & 9 & 56,2 & 14 & 56 & 15 & 62,5 & 5 & 41,6 \\
\hline Gesamt & & $1 \%$ & & $96 \%$ & & $81 \%$ & & $5,84 \%$ & & $.75 \%$ & & $76 \%$ & & $8 \%$ \\
\hline
\end{tabular}

Tabelle 2: Altersverteilung in Zehnjahresintervallen. $n=101$

Gesamt: $101(100 \%) \quad$ Frauen: 60 (59,4\%) Männer: $41(40,6 \%)$ 


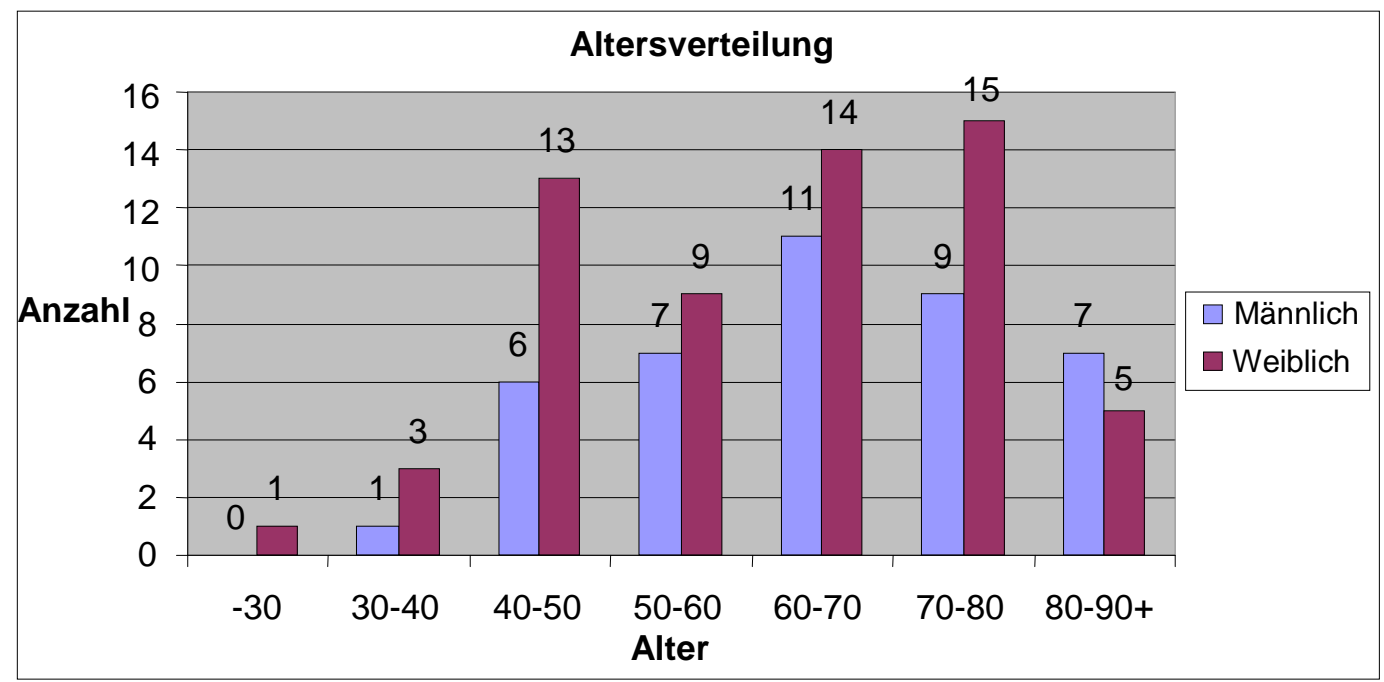

Abbildung 1: Altersverteilung der Patienten nach Geschlechtern differenziert

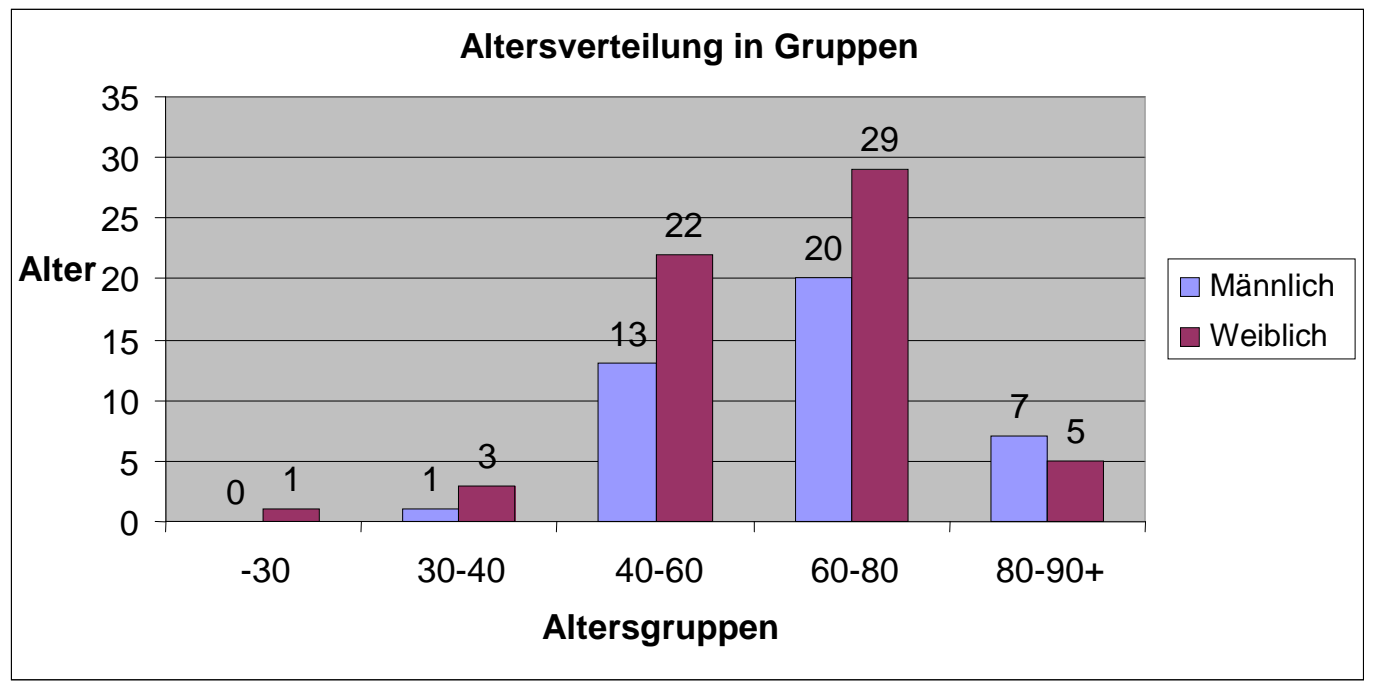

Abbildung 2: Altersverteilung der Patienten in Altersgruppen und nach Geschlechtern differenziert

\subsection{Häufigkeitsverteilung zugrundeliegender Diagnosen}

Der palliativmedizinischen Behandlung und Betreuung lag im überwiegenden Teil der untersuchten Patienten eine primär inoperable / metastasierte oder eine rezidivierte / sekundär metastasierte Tumorerkrankung zugrunde (Tabelle 3). 
Mit 30 betroffenen Patienten von 101 stellten bösartige Neubildungen des Gastrointestinaltraktes (C15 - C26 nach ICD 10) die häufigsten Diagnosen dar, gefolgt von bösartigen Neubildungen des Respirationstraktes (22 Patienten). Tumore der Brust (C50) liegen mit 14 Erkrankungen an der dritten Stelle der angetroffenen Neubildungen. Vier Patienten hatten Tumore des männlichen Genitaltraktes (C60 - C63) und sechs Patienten hatten Tumore des weiblichen Genitaltraktes (C51 - C58). Weiterhin wurden fünf Patienten mit Tumoren der Haut (C43 - C44), 2 Patienten mit Tumoren von Mund und Rachen (C00 C14), 6 Patienten mit Tumoren des harnableitenden Systems (C64 - C68), 5 Patienten mit Tumoren des Zentralen Nervensystems (C69 - C72) sowie 6 Patienten mit Lymphomen und Leukämien (C81 - C96) angetroffen.

\begin{tabular}{|c|c|c|}
\hline ICD10_Code & Diagnose & $\begin{array}{c}\text { Anz. } \\
\text { Erkrankungen }\end{array}$ \\
\hline C04 & Bösartige Neubildung des Mundbodens & 1 \\
\hline C10 & Bösartige Neubildung des Oropharynx & 1 \\
\hline C15 & Bösartige Neubildung des Ösophagus & 4 \\
\hline C16 & Bösartige Neubildung des Magens & 6 \\
\hline C18 & Bösartige Neubildung des Kolons & 4 \\
\hline C20 & Bösartige Neubildung des Rektums & 2 \\
\hline C21 & Bösartige Neubildung des Anus und des Analkanals & 1 \\
\hline C22 & Bösartige Neubildung der Leber und der intrahepatischen Gallengänge & 1 \\
\hline C24.8 & Bösartige Neubildung: Gallenwege, mehrere Teilbereiche überlappend & 1 \\
\hline C24.9 & Bösartige Neubildung: Gallenwege, nicht näher bezeichnet & 3 \\
\hline C25 & Bösartige Neubildung des Pankreas & 22 \\
\hline C34 & Bösartige Neubildung der Bronchien und der Lunge & 4 \\
\hline C43 & Bösartiges Melanom der Haut & 1 \\
\hline C49.9 & Bösartige Neubildung:(Leiomyosarkom) Bindegewebe und andere Weichteilgewebe & 14 \\
\hline C50 & Bösartige Neubildung der Brustdrüse [Mamma] & 1 \\
\hline C54 & Bösartige Neubildung des Corpus uteri & 1 \\
\hline C54.1 & Bösartige Neubildung: Endometrium & 4 \\
\hline C56 & Bösartige Neubildung des Ovars & 4 \\
\hline C61 & Bösartige Neubildung der Prostata & 2 \\
\hline C64 & Bösartige Neubildung der Harnblase & 3 \\
\hline C67 & Bösartige Neubildung des Gehirns & 5 \\
\hline C71 & CUP Syndrom & 2 \\
\hline C80 & Pösartige Neubildung der Niere, ausgenommen Nierenbecken & 1 \\
\hline C84.5 & Akute Myeloische Leukämie & 4 \\
\hline C92 & Sonstige und nicht näher bezeichnete T-Zell-Lymphome & 2 \\
\hline
\end{tabular}

Tabelle 3: Häufigkeit zugrundeliegender Diagnosen (ICD 10) 


\subsection{Medikation und enorale Symptome}

$\mathrm{Zu}$ den am häufigsten eingesetzten Medikamenten gehören Antidepressiva, starke opioidhaltige Analgetika, Sedativa und Neuroleptika (Tabelle 5).

\begin{tabular}{|c|c|c|c|}
\hline Medikament & Gesamt & Dysgeusie & Xerostomie \\
\hline Lorazepam (z.B. Tavor®) & 63 & 40 & 51 \\
\hline Hydromorphon (z.B. Palladon®) & 21 & 9 & 17 \\
\hline Morphinsulfat (z.B. Sevredol®) & 33 & 24 & 23 \\
\hline Morphin (z.B. MSI®) & 15 & 13 & 14 \\
\hline Haloperidol (z.B. Haldol®) & 21 & 17 & 19 \\
\hline Fentanyl (z.B. Durogesic TTS $®$ ) & 12 & 6 & 7 \\
\hline Levomethadon (z.B. L-Polamidon®) & 12 & 7 & 12 \\
\hline Amitriptylin (z.B. Saroten $®)$ & 16 & 8 & 13 \\
\hline Butylscopolaminiumbromid (z.B. Buscopan®) & 6 & 3 & 5 \\
\hline
\end{tabular}

Tabelle 5: Begleitende Medikation

\subsection{MIDOS: Symptome und Befinden in der Selbsteinschätzung}

In den nachfolgenden Tabellen (Tabellen 5, 6, 7) sind die Ergebnisse des Minimalen Dokumentationssystems MIDOS und die Durchschnittswerte zusammengefasst. Die Werte für Schwäche (Ø 2,24) und Müdigkeit (Ø 2,09) sind am auffälligsten. Der niedrigste Wert ist die Bewertung von Angst (Ø 0,72). Bei der Frage nach dem Befinden (Ø 3,0) wurde am häufigsten „mittel“" angegeben.

Insgesamt 46 Patienten füllten den Fragebogen selbst aus, wobei auch hier der Untersucher Hilfestellung geben musste. Bei 55 Patienten wurde der Bogen von dem Untersucher, entsprechend der Angaben der Patienten ausgefüllt.

\begin{tabular}{|l|c|c|c|c|c|}
\hline Symptome & keine (0) & Leichte (1) & Mittlere (2) & starke (3) & Durchschnittswert \\
\hline Müdigkeit & 7 & 18 & 34 & 42 & 2,09 \\
\hline Übelkeit & 47 & 25 & 14 & 15 & 0,97 \\
\hline Verstopfung & 50 & 24 & 13 & 14 & 0,91 \\
\hline Luftnot & 48 & 26 & 11 & 16 & 0,95 \\
\hline Schwäche & 4 & 18 & 28 & 51 & 2,24 \\
\hline Angst & 61 & 15 & 17 & 8 & 0,72 \\
\hline Mittelstarker Schmerz & & & & & 3,45 \\
\hline Stärkste Schmerzen & & & & & 2,1 \\
\hline
\end{tabular}

Tabelle 6: Patienteneinschätzung eigener Symptome 


\begin{tabular}{|l|c|c|c|c|c|c|}
\hline & sehr schlecht (5) & schlecht (4) & mittel (3) & gut (2) & sehr gut (1) & Durchschnitt \\
\hline Befinden & 1 & 25 & 52 & 19 & 4 & 3 \\
\hline
\end{tabular}

Tabelle 7: Patienteneinschätzung des allgemeinen Befindens

\begin{tabular}{|l|c|c|c|c|c|c|}
\hline & Selbst & Sprachprobleme & Schwäche & Kognitive Störungen & Patient lehnt ab & keine Zeit \\
\hline Erfassung & 46 & 0 & 52 & 3 & 0 & 0 \\
\hline
\end{tabular}

Tabelle 8: Art der Erfassung / Grund der Fremderfassung

\subsection{Intensität der oralen Missempfindungen}

In der unten dargestellten Tabelle 9 werden die jeweils angegebenen Stärken der oralen Missempfindungen, die von den Patienten auf einer Numerischen Rating Skala von 0 bis 10 angegeben wurden, dargestellt.

Hier fällt auf, dass die 25 Patienten, die keine oralen Missempfindungen angegeben haben (NRS 0) trotzdem in 15 Fällen eine Xerostomie, in 10 Fällen eine Dysgeusie in zwei Fällen eine Dysphagie, in vier Fällen Brennen und in drei Fällen Mundgeruch beschrieben.

Xerostomie und Dysgeusie zählten zu den am häufigsten angegebenen Symptomen.

\begin{tabular}{|l|c|c|c|c|c|}
\hline $\begin{array}{c}\text { Intensität und Häufigkeit }(\mathbf{n}=) \text { der oralen } \\
\text { Missempfindung }\end{array}$ & Xerostomie & Dysgeusie & Dysphagie & Brennen & Mundgeruch \\
\hline $\mathbf{0}(\mathrm{n}=25) \rightarrow$ & 15 & 10 & 2 & 4 & 3 \\
\hline $\mathbf{1}(\mathrm{n}=18) \rightarrow$ & 16 & 11 & 3 & 5 & 5 \\
\hline $\mathbf{2}(\mathrm{n}=4) \rightarrow$ & 4 & 3 & 0 & 2 & 2 \\
\hline $\mathbf{3}(\mathrm{n}=2) \rightarrow$ & 2 & 2 & 1 & 0 & 0 \\
\hline $\mathbf{4}(\mathrm{n}=6) \rightarrow$ & 5 & 4 & 4 & 2 & 0 \\
\hline $\mathbf{5}(\mathrm{n}=22) \rightarrow$ & 19 & 19 & 5 & 5 & 7 \\
\hline $\mathbf{6}(\mathrm{n}=0) \rightarrow$ & 0 & 0 & 0 & 0 & 0 \\
\hline $\mathbf{7}(\mathrm{n}=1) \rightarrow$ & 1 & 1 & 1 & 0 & 0 \\
\hline $\mathbf{8}(\mathrm{n}=4) \rightarrow$ & 4 & 2 & 3 & 0 & 0 \\
\hline $\mathbf{9}(\mathrm{n}=4) \rightarrow$ & 4 & 2 & 4 & 1 & 1 \\
\hline $\mathbf{1 0}(\mathrm{n}=15) \rightarrow$ & 13 & 14 & 6 & 6 & 8 \\
\hline
\end{tabular}

Tabelle 9: Stärke der oralen Missempfindung 
Zur weiteren Veranschaulichung sind die Stärken der Missempfindungen und die jeweiligen Symptome aus der obigen Tabelle 9 in Gruppen zusammengefasst (Tabelle 10, Abbildung 3).

Hierbei ist zu erkennen, dass vier annähernd gleich große Gruppen entstehen. Die Gruppe mit der mittleren Stärke der oralen Missempfindung (NRS 4-7, $\mathrm{n}=29$ ) ist am stärksten vertreten. Die kleinste Gruppe stellt die Gruppe mit den stärksten oralen Missempfindungen (NRS 8-10, $\mathrm{n}=23)$ dar.

\begin{tabular}{|c|c|c|c|c|c|}
\hline $\begin{array}{c}\text { Intensität und Häufigkeit (Gruppenvergleich) } \\
\text { der oralen Missempfindung }\end{array}$ & Xerostomie & Dysgeusie & Dysphagie & Brennen & Mundgeruch \\
\hline $\mathbf{0}=$ keine orale Missempf. $(n=25) 24,75 \%$ & 15 & 10 & 2 & 4 & 3 \\
\hline $\mathbf{1 - 3}=$ leichte orale Missempf. $(n=24) 23,76 \%$ & 22 & 16 & 4 & 7 & 7 \\
\hline $\mathbf{4 - 7}=$ mittlere orale Missempf. $(n=29) 28,71 \%$ & 25 & 24 & 10 & 7 & 7 \\
\hline $\mathbf{8 - 1 0}=$ starke orale Missempf. $(n=23) 22,77 \%$ & 21 & 18 & 13 & 7 & 9 \\
\hline
\end{tabular}

Tabelle 10:Stärke der oralen Missempfindung in Gruppen

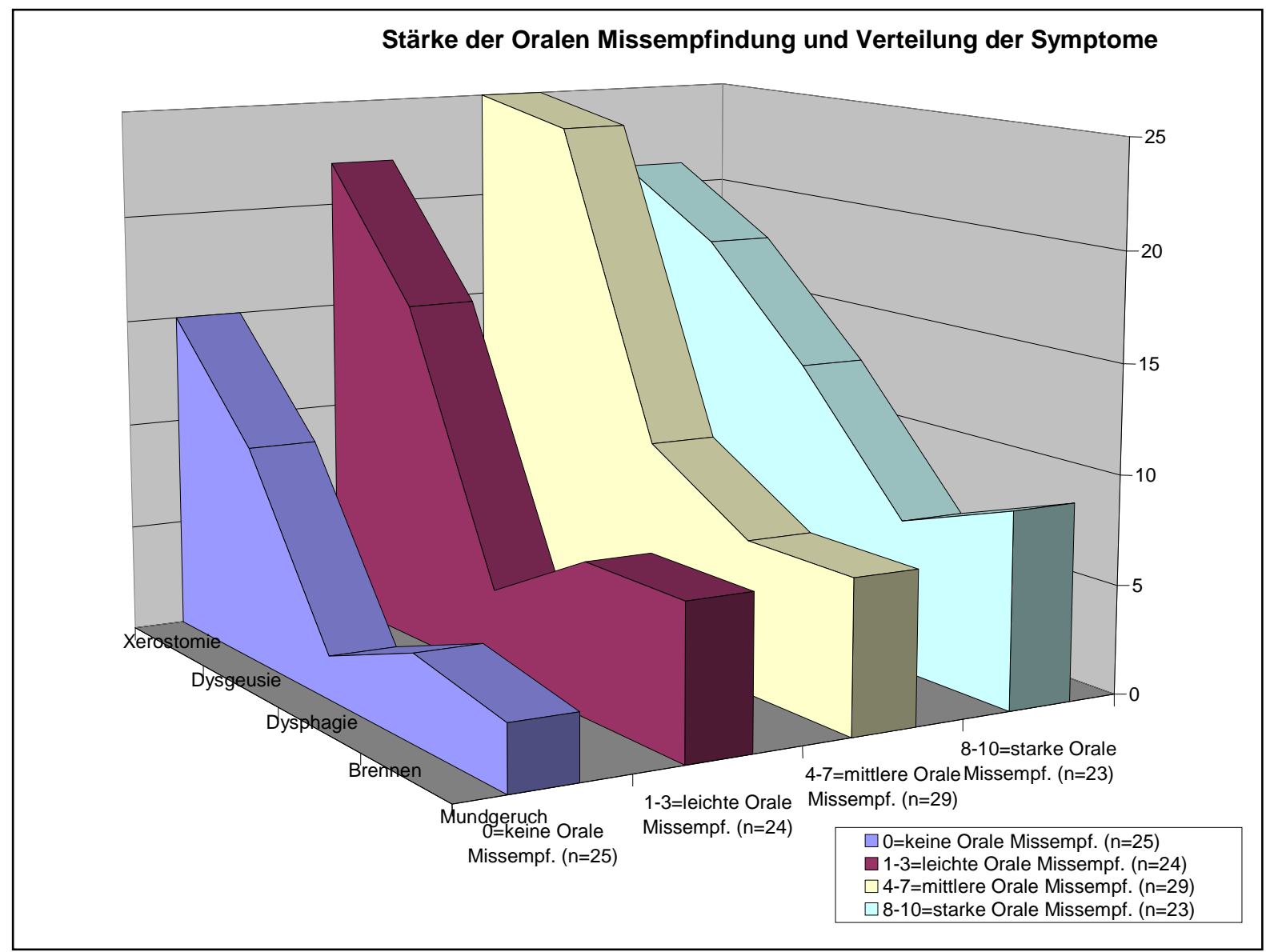

Abbildung 3: Intensität der oralen Missempfindung (Gruppen) und Verteilung der Symptome 


\subsection{Klinische Befunde}

\begin{tabular}{|c|c|}
\hline $\begin{array}{c}\text { Klinische } \\
\text { Befunde }\end{array}$ & Gesamt \\
\hline $\begin{array}{c}\text { soortypische } \\
\text { Beläge (Zunge) }\end{array}$ & 23 \\
\hline $\begin{array}{c}\text { Beläge } \\
\text { anderweitig } \\
\text { (Zunge) }\end{array}$ & 81 \\
\hline $\begin{array}{c}\text { soortypische } \\
\text { Beläge } \\
\text { (Schleimhaut der } \\
\text { Mundhöhle) }\end{array}$ & 32 \\
\hline $\begin{array}{c}\text { Beläge } \\
\text { anderweitig } \\
\text { (Schleimhaut der } \\
\text { Mundhöhle) }\end{array}$ & 63 \\
\hline $\begin{array}{c}\text { Gingiva gerötet } \\
\text { Gingiva } \\
\text { geschwollen }\end{array}$ & 62 \\
\hline $\begin{array}{c}\text { gingivales } \\
\text { Hämatom }\end{array}$ & 19 \\
\hline Druckstelle & 15 \\
\hline Aphthe & 14 \\
\hline Gingiva normal & 36 \\
\hline $\begin{array}{c}\text { Schleimhaut } \\
\text { normal }\end{array}$ & 32 \\
\hline
\end{tabular}

Bei der Untersuchung der Mundhöhle sind unterschiedlich stark ausgeprägte Veränderungen beobachtet worden. Besonders auffällig sind starke Beläge in der Mundhöhle, dabei sind sowohl die Zunge sowie auch der Rest der Mundschleimhaut betroffen (Tabelle 11). Bei 62 Patienten konnte eine gerötete Gingiva, bei 19 eine geschwollene (hyperplasische) Gingiva sowie bei fünf Patienten ein gingivales Hämatom festgestellt werden. Weiterhin wurden bei 15 Patienten leicht bis mittelstark ausgeprägte Druckstellen sowie bei 15 Patienten eine Aphthe beobachtet.

Eine normale, reizfreie Gingiva war bei 36 Patienten und eine reizfreie Mundschleimhaut bei 32 Patienten zu sehen.

Tabelle 11: Häufigkeit der klinischen Befunde

\subsection{Vergleich Pilzbefunde und Beläge der Mundhöhle}

\begin{tabular}{|l|c|c|}
\hline & Gesamt & Pilze \\
\hline soortypische Beläge auf der Zunge & 23 & 20 \\
\hline soortypische Beläge auf der Schleimhaut & 32 & 28 \\
\hline anderweitige Beläge auf der Zunge & 81 & 60 \\
\hline anderweitige Beläge auf der Schleimhaut & 63 & 51 \\
\hline
\end{tabular}

Tabelle 12: Lokalisation und Art der Beläge in Korrelation mit gleichzeitigem Pilznachweis

Beim Abgleich klinischer Belagbefunde mit etwaig begleitendem Pilznachweis (Tabelle 12) lassen sich folgende Aussagen treffen:

- Insgesamt hatten 23 von den 101 untersuchten Patienten soortypische Beläge auf der Zunge. Bei diesen 23 Patienten, lag bei 20 Patienten ein Pilzbefund vor (Tabelle 12).

- Insgesamt hatten 32 von den 101 untersuchten Patienten soortypische Beläge auf der Schleimhaut. Innerhalb dieser 32 Patienten lag bei 28 Patienten ein Pilzbefund vor.

- Insgesamt hatten 81 von den 101 untersuchten Patienten anderweitige Beläge auf der Zunge. Bei diesen 81 Patienten lag bei 60 Patienten ein Pilzbefund vor.

- Insgesamt hatten 63 von den 101 untersuchten Patienten anderweitige Beläge auf der Schleimhaut. Innerhalb dieser 63 Patienten lag bei 51 Patienten ein Pilzbefund vor. 


\subsection{Chemotherapie/Radiatio und Symptomprävalenz}

\begin{tabular}{|l|c|c|c|c|c|c|c|c|}
\hline & Xerostomie & Dysgeusie & Mundgeruch & Dysphagie & Mykose & $\begin{array}{c}\text { abw. bakt. } \\
\text { Besiedelung }\end{array}$ & HSV & Gesamt \\
\hline $\begin{array}{l}\text { Chemotherapie } \\
\text { (Zeitraum: aktuell } \\
\text { bis 6 Wochen } \\
\text { zurückliegend) }\end{array}$ & 21 & 18 & 7 & 6 & 16 & 9 & 2 & 25 \\
\hline $\begin{array}{l}\text { Radiatio } \\
\text { (Zeitraum: aktuell } \\
\text { bis 6 Wochen } \\
\text { zurückliegend) }\end{array}$ & 14 & 11 & 2 & 6 & 12 & 3 & 4 & 15 \\
\hline
\end{tabular}

Tabelle 13: Symptomhäufigkeit und Chemotherapie / Radiatio

In der obigen Tabelle (Tabelle 13) sind die jeweiligen Gesamtzahlen der Patienten aufgeführt, welche zum Zeitpunkt der Untersuchung bzw. bis zu 6 Wochen davor eine Chemotherapie $(n=25)$ oder Radiatio $(n=15)$ hatten. Die jeweiligen Symptomhäufigkeiten sind aufgeführt.

25 Patienten hatten - im Zeitraum bis sechs Wochen vor der Untersuchung - eine Chemotherapie. Von diesen gaben 21 eine Xerostomie, 18 eine Dysgeusie an und bei 16 Patienten lag ein positiver Pilzbefund vor.

15 Patienten hatten - im Zeitraum bis sechs Wochen vor der Untersuchung - eine Bestrahlung. Von diesen gaben 14 eine Xerostomie, 11 eine Dysgeusie an und bei 12 Patienten lag ein positiver Pilzbefund vor.

\subsection{Zahnmedizinische Befunderhebung}

Bei der zahnärztlichen Untersuchung der Patienten wurde in Anbetracht der angestrebten kurzen Untersuchungsdauer, die Anzahl der Zähne, Art des Zahnersatzes, DMF-T-Index sowie eine visuelle Beurteilung der Mundhygiene ohne Plaqueanfärbung durchgeführt (Tabelle 14).

Der DMF-T-Index steigt mit dem Alter der Patienten, was sich mit einer fortschreitenden Zahnlosigkeit und weitgehender prothetischer Versorgung erklären lässt.

Eine Ausnahme stellt jedoch ein Patient dar, der jünger als 30 Jahre alt ist und einen hohen DMF-T-Index (18) aufweist. Mundhygiene der Patienten ist in den jeweiligen Altersgruppen mit "gut", "mittel" und "schlecht" bewertet worden. In der zahlenmäßig zweitstärksten Gruppe von 40 bis 60 Jahren $(n=35)$ haben $46 \%$ eine gute, $23 \%$ eine mittlere und $31 \%$ eine schlechte Mundhygiene. In der am stärksten vertretenen Gruppe der Patienten im Alter von 60 bis 80 Jahren $(n=49)$ haben $35 \%$ eine gute, $43 \%$ eine mittlere und $22 \%$ eine schlechte Mundhygiene.

Erwartungsgemäß nimmt die Häufigkeit der prothetischen Versorgung mit steigendem Alter der Patienten zu. 


\begin{tabular}{|c|c|c|c|c|c|c|c|c|}
\hline Alter & $\begin{array}{c}\text { Oberkiefer } \\
\text { Totalprothese }\end{array}$ & $\begin{array}{c}\text { Unterkiefer } \\
\text { Totalprothese }\end{array}$ & $\begin{array}{l}\text { Oberkiefer } \\
\text { Teilprothese }\end{array}$ & $\begin{array}{c}\text { Unterkiefer } \\
\text { Teilprothese }\end{array}$ & Brücke & Krone & $\begin{array}{l}\text { DMF- } \\
\text { T } \varnothing\end{array}$ & $\begin{array}{c}\text { Mund- } \\
\text { hygiene }\end{array}$ \\
\hline $\begin{array}{c}<30(\mathrm{n}= \\
1)\end{array}$ & 0 & 0 & 0 & 0 & 0 & 0 & $\varnothing 18$ & schlecht \\
\hline $\begin{array}{c}30 \text { bis } 40 \\
(n=4)\end{array}$ & 0 & 0 & 0 & 0 & 0 & 5 & $\varnothing 7.5$ & $\begin{array}{c}\text { gut }=3 \\
(75,00 \%) \\
\text { mittel }=0 \\
(0,00 \%) \\
\text { schlecht }=1 \\
(25,00 \%)\end{array}$ \\
\hline $\begin{array}{c}40 \text { bis } 60 \\
(n=35)\end{array}$ & 4 & 3 & 6 & 4 & 22 & 96 & $\begin{array}{c}\varnothing \\
17,9\end{array}$ & $\begin{array}{c}\text { gut }=16 \\
(45,71 \%) \\
\text { mittel = } 8 \\
(22,85 \%) \\
\text { schlecht = } \\
11(31,42 \%) \\
\end{array}$ \\
\hline $\begin{array}{c}60 \text { bis } 80 \\
(n=49)\end{array}$ & 21 & 11 & 11 & 15 & 23 & 90 & $\begin{array}{c}\varnothing \\
22,2\end{array}$ & $\begin{array}{c}\text { gut }=17 \\
(34,69 \%) \\
\text { mittel }=21 \\
(42,85 \%) \\
\text { schlecht = } \\
11(22,44 \%) \\
\end{array}$ \\
\hline $\begin{array}{c}>80 \\
(n=12)\end{array}$ & 5 & 2 & 6 & 5 & 7 & 21 & $\begin{array}{c}\varnothing \\
24.8\end{array}$ & $\begin{array}{c}\text { gut }=4 \\
(33,33 \%) \\
\text { mittel }=2 \\
(16.66 \%) \\
\text { schlecht }=6 \\
(50,00 \%) \\
\end{array}$ \\
\hline
\end{tabular}

Tabelle 14: Altersgruppen, Art des Zahnersatzes und Mundhygiene

\subsection{Ergebnisse mikrobiologischer Untersuchungen}

Im Rahmen der mikrobiologischen Untersuchung erfolgte bei allen 101 teilnehmenden Patienten ein Abstrich in der Mundhöhle. Neben der physiologischen Mundflora wurden insgesamt 18 in den angelegten Kulturen dominierende Keime nachgeweisen. Bei 34 Patienten war eine von dem physiologischen Standard abweichende Mundflora fest zu stellen. Innerhalb dieser Gruppe $(\mathrm{n}=34)$ wurden bei neun Patienten zwei abweichende Keime und bei zwei Patienten jeweils drei abweichende Keime festgestellt. Am stärksten vertreten war Streptococcus viridans in signifikanter Keimzahl, gefolgt von E. coli und Klebsiella pneumoniae (Tabelle 15). 


\begin{tabular}{|c|c|c|c|c|c|}
\hline & $\begin{array}{c}\text { Von der physiologischen Norm abweichende } \\
\text { Keimbesiedlung }\end{array}$ & gesamt & reichlich & mäßig & vereinzelt \\
\hline 1 & Streptococcus viridans & 8 & 3 & 4 & 1 \\
\hline 2 & Escherichia coli & 6 & 2 & 3 & 1 \\
\hline 3 & Klebsiella pneumoniae & 5 & 1 & 3 & 1 \\
\hline 4 & Enterobacter cloacae & 3 & 1 & 1 & 1 \\
\hline 5 & Enterococcus faecalis & 3 & 1 & 2 & 3 \\
\hline 6 & Enterococcus species & 3 & & 2 & 3 \\
\hline 7 & Methicillinresist. Staphylococcus aureus & 3 & & & 2 \\
\hline 8 & Neisseria species & 3 & & & \\
\hline 9 & Staphylococcus aureus & 3 & & 1 & \\
\hline 10 & Klebsiella oxytoca & 2 & & 2 & 1 \\
\hline 11 & Koag. neg. Staphylokokken & 2 & & 1 & 1 \\
\hline 12 & Pseudomonas aeruginosa & 2 & 1 & & \\
\hline 13 & Citrobacter freundii & 1 & & & \\
\hline 14 & Corynebacterium species & 1 & & 1 & \\
\hline 15 & Enterococcus faecium / VRE-Stamm & 1 & & & \\
\hline 16 & Moraxella spec. & 1 & & & \\
\hline 17 & Pseudomonas putida & 1 & & 1 & \\
\hline 18 & Serratia liquefaciens & 1 & & & 1 \\
\hline
\end{tabular}

Tabelle 15: Bakterielles Erregerspektrum

Bei 34 von 101 Patienten war eine Abweichung von der physiologischen Norm fest zu stellen. Bei diesen 34 Patienten kam mindestens ein von der physiologischen Mundflora abweichender Keim vor, neun Personen wiesen zwei abweichende Keime und zwei Personen drei abweichende Keime auf.

\subsection{Mikrobiologische Mehrfachbesiedelung}

In der mikrobiologischen Untersuchung hatten 34 der 101 Patienten mindestens einen abweichenden Keim. In neun Fällen kamen zwei abweichende Keime vor, wobei in drei Fällen die gleiche Keimkombination (Tabelle 16), nämlich Streptococcus viridans sowie Neisseria species vorkamen.

Bei den sechs anderen Fällen in der Gruppe mit je zwei abweichenden Keimen sehen die Keimkonstellationen wie folgt aus:

- $\quad$ Koagulase negative Staphylokokken - Corynebacterium species

- Klebsiella oxytoca - Klebsiella pneumoniae

- $\quad$ Streptococcus viridans - Klebsiella pneumoniae

- $\quad$ Staph. aureus - Enterococcus species

- $\quad$ E. coli-Enterococcus species

- $\quad$ Enterobacter cloacae - Enterbacter faecalis 
In 2 Fällen kamen drei abweichende Keime vor, mit folgender Keimkombination:

Enterobacter cloacae - Pseudomonas putida - Klebsiella oxytoca

Streptococcus viridans - MRSA / Staph. aureus - Moraxella spec.

\begin{tabular}{|c|c|c|c|c|c|}
\hline Gesamt & Keime in Kombination & + & ++ & ++++ & Hefen \\
\hline \multirow{6}{*}{3} & \multirow{2}{*}{$\begin{array}{l}\text { Streptococcus viridans } \\
\text { Neisseria species }\end{array}$} & & $\bullet$ & & \multirow{2}{*}{$\mathrm{Ja}$} \\
\hline & & - & & & \\
\hline & \multirow{2}{*}{$\begin{array}{c}\text { Streptococcus viridans } \\
\text { Neisseria species }\end{array}$} & & & - & \multirow{2}{*}{ Nein } \\
\hline & & - & & & \\
\hline & \multirow{2}{*}{$\begin{array}{c}\text { Streptococcus viridans } \\
\text { Neisseria species }\end{array}$} & & & - & \multirow{2}{*}{ Nein } \\
\hline & & $\bullet$ & & & \\
\hline \multirow{2}{*}{1} & Koag.neg.Staphylokokken & - & & & \multirow{2}{*}{$\mathrm{Ja}$} \\
\hline & Corynebacterium species & & - & & \\
\hline \multirow{2}{*}{1} & Klebsiella oxytoca & & - & & \multirow{2}{*}{$\mathrm{Ja}$} \\
\hline & Klebsiella pneumoniae & & - & & \\
\hline \multirow{2}{*}{1} & \multirow{2}{*}{$\begin{array}{l}\text { Streptococcus viridans } \\
\text { Klebsiella pneumoniae }\end{array}$} & & & - & \multirow{2}{*}{$\mathrm{Ja}$} \\
\hline & & & $\bullet$ & & \\
\hline \multirow{2}{*}{1} & \multirow{2}{*}{$\begin{array}{c}\text { Staph.aureus } \\
\text { Enterococcus species }\end{array}$} & - & & & \multirow{2}{*}{$\mathrm{Ja}$} \\
\hline & & & - & & \\
\hline \multirow{2}{*}{1} & \multirow{2}{*}{$\begin{array}{c}\text { Escherichia coli } \\
\text { Enterococcus species }\end{array}$} & & - & & \multirow{2}{*}{ Nein } \\
\hline & & $\bullet$ & & & \\
\hline \multirow{2}{*}{1} & \multirow{2}{*}{$\begin{array}{l}\text { Enterobacter cloacae } \\
\text { Enterococcus faecalis }\end{array}$} & - & & & \multirow{2}{*}{$\mathrm{Ja}$} \\
\hline & & & $\bullet$ & & \\
\hline \multirow{3}{*}{1} & Enterobacter cloacae & & - & & \multirow{3}{*}{$\mathrm{Ja}$} \\
\hline & Pseudomonas putida & & $\bullet$ & & \\
\hline & Klebsiella oxytoca & & $\bullet$ & & \\
\hline \multirow{3}{*}{1} & Streptococcus viridans & - & & & \multirow{3}{*}{$\mathrm{Ja}$} \\
\hline & Methicillinresist. Staphylococcus aureus & $\bullet$ & & & \\
\hline & Moraxella species & - & & & \\
\hline
\end{tabular}

Tabelle 16: Pathogene Keime in Kombination

\subsection{Vergleich Untersuchungsgruppe vs. Referenzgruppe}

Wie bereits im Kapitel 4.2. erwähnt, wurden uns kollegialerweise vom MedizinischMikrobiologischen Institut der Georg-August-Universität Göttingen Ergebnisse einer Kohortenuntersuchung zur Verfügung gestellt, welche uns als Referenzgruppe diente (Tabelle 17, Anlage). Bei einem direkten Vergleich der Referenzgruppe (gesunde Probanden) und der Untersuchungsgruppe (Patienten der Palliativstation) ist der hohe Anteil $(71,28 \%)$ an positiven Hefebefunden in der Untersuchungsgruppe auffällig.

Im Bereich der von der physiologischen Mundflora abweichenden Keime ist in der Referenzgruppe ein höherer Prozentsatz an positiven Befunden zu beobachten (Tabelle 18). 


\begin{tabular}{|c|c|c|c|c|c|}
\hline & Erregerspektrum & gesamt & reichlich & mäßig & vereinzelt \\
\hline 1 & Streptococcus viridans & 11 & 11 & & \\
\hline 2 & Escherichia coli & 5 & 2 & & 3 \\
\hline 3 & Klebsiella pneumoniae & 5 & 1 & & 5 \\
\hline 4 & Enterococcus faecalis & 5 & & & 4 \\
\hline 5 & Neisseria species & 4 & & & 3 \\
\hline 6 & Staphylococcus aureus & 3 & & & 6 \\
\hline 7 & Koag. neg. Staphylokokken & 6 & & & 3 \\
\hline 8 & Pseudomonas aeruginosa & 1 & & & \\
\hline 9 & Moraxella catarrhalis & 4 & & & \\
\hline 10 & Streptococcus pneumoniae & 3 & & & \\
\hline 11 & Serratia marcescens & 1 & & & \\
\hline 12 & Streptokokken der Gruppe A & 3 & & & \\
\hline
\end{tabular}

Tabelle 17: Mikrobiologie der Referenzgruppe

Im Direktvergleich zwischen gesunden Probanden und der Untersuchungsgruppe Palliativstation fanden sich unterschiedliche Prävalenzen bezüglich der von der physiologischen Mundflora abweichenden Keime (Tabelle 18).

\begin{tabular}{|c|c|c|}
\hline & $\begin{array}{c}\text { Patienten Palliativstation } \\
(\mathbf{n = 1 0 1 )}\end{array}$ & $\begin{array}{c}\text { Kontrollgruppe gesunder Probanden } \\
(\mathbf{n}=\mathbf{1 0 0})\end{array}$ \\
\hline Hefen & $72(71,28 \%)$ & $37(37 \%)$ \\
\hline abweichende Bakterienflora & $34(33,66 \%)$ & $51(51 \%)$ \\
\hline physiologische Bakterienflora & $67(66,33 \%)$ & $49(49 \%)$ \\
\hline
\end{tabular}

Tabelle 18: Vergleich Untersuchungsgruppe / Referenzgruppe 


\subsection{Nachweis von Herpes-simplex-Virus}

Von den 101 mittels PCR untersuchten Rachenspüllösungen zwecks Nachweises von Herpessimplex-Viren konnten bei 19 Patienten positive Befunde festgestellt werden (Tabelle 19).

\begin{tabular}{|c|c|c|c|}
\hline Bogennummer & HSV PCR & Konzentration & Pilze \\
\hline 4 & Typ1 & $9 \times 10^{4}$ & mein \\
\hline 6 & Typ1 & $1,8 \times 10^{3}$ & mäßig \\
\hline 11 & Typ1 & $1,1 \times 10^{7}$ & nein \\
\hline 12 & Typ1 & $3,4 \times 10^{5}$ & nein \\
\hline 15 & Typ1 & $6 \times 10^{2}$ & nein \\
\hline 18 & Typ1 & $1 \times 10^{3}$ & nein \\
\hline 19 & Typ1 & $9,8 \times 10^{4}$ & nein \\
\hline 20 & Typ1 & $7,0 \times 10^{2}$ & mäßig \\
\hline 31 & Typ1 & $1,4 \times 10^{6}$ & mäßig \\
\hline 45 & Typ2 & $3 \times 10^{6}$ & nein \\
\hline 60 & Typ1 & $1,1 \times 10^{7}$ & reichlich \\
\hline 61 & Typ1 & $2,5 \times 10^{4}$ & gering \\
\hline 65 & Typ1 & $9,4 \times 10^{2}$ & mäßig \\
\hline 67 & Typ1 & $1,5 \times 10^{3}$ & mäßig \\
\hline 69 & Typ1 & $3,5 \times 10^{3}$ & reichlich \\
\hline 71 & Typ1 & $3,6 \times 10^{6}$ & mäßig \\
\hline 80 & Typ1 & $4,8 \times 10^{5}$ & $2,9 \times 10^{4}$ \\
\hline 100 & Typ1 & $7,3 \times 10^{3}$ & \\
\hline
\end{tabular}

Tabelle 19: HSV Infektion incl. Konzentration sowie Pilzbefall

\subsection{Mykosen}

Das auffälligste Ergebnis in der mykologischen Diagnostik ist die signifikant hohe Anzahl von Hefebefunden, welche nachfolgend näher beschrieben sind (Tabelle 20).

Von den 101 untersuchten Patienten wurden 72 Patienten positiv auf Hefepilze getestet. Bei 62 Patienten wurde nur eine Hefeart festgestellt (Candida albicans).

Bei 10 Patienten kamen zwei Hefearten vor:
1 Fall mit Candida lambica + Candida albicans
2 Fälle mit Candida albicans + Candida krusei
5 Fälle mit Candida albicans + Candida glabrata
2 Fälle mit Candida tropicalis + Candida glabrata 


\begin{tabular}{|c|c|c|c|}
\hline \multicolumn{3}{|c|}{ Hefen (n= 72) } \\
\hline & gering & mäßig & reichlich \\
\hline Candida albicans & 39 & 17 & \\
\hline $\begin{array}{l}\text { Candida albicans } \\
\text { Candida lambica }\end{array}$ & & 1 & \\
\hline $\begin{array}{l}\text { Candida albicans } \\
\text { Candida krusei }\end{array}$ & & 1 & 1 \\
\hline $\begin{array}{l}\text { Candida albicans } \\
\text { Candida glabrata }\end{array}$ & & 4 & \\
\hline $\begin{array}{l}\text { Candida glabrata } \\
\text { Candida krusei }\end{array}$ & & 2 & \\
\hline $\begin{array}{l}\text { Candida tropicalis } \\
\text { Candida glabrata }\end{array}$ & 39 & 25 & \\
\hline Häufigkeit Gesamt & & & \\
\hline
\end{tabular}

Tabelle 20: Mykosen und Kombinationen

\subsection{Korrelation von bakteriellen Befunden und klinischen Symptomen}

Bei der Verknüpfung der verschiedenen subjektiven Symptome, klinischen Befunde und mikrobiologischen Ergebnisse wurden insgesamt acht statistisch signifikante Korrelationen gefunden (Tabelle 21). Nur bei zwei Korrelationen (soortypische Beläge Zunge / Xerostomie, anderweitig belegte Zunge / Dysgeusie) muss man aufgrund des Signifikanzniveaus eher von einer Tendenz ausgehen.

\begin{tabular}{|c|l|}
\hline Merkmale & \multicolumn{1}{|c|}{ Signifikanzniveau } \\
\hline Pilze / Dysgeusie & $\mathrm{p}<, 03386$ \\
\hline Pilze / Xerostomie & $\mathrm{p}<, 02766$ \\
\hline Abweichende bakt. Besiedlung / Dysgeusie & $\mathrm{p}<, 02181$ \\
\hline soortypische Beläge Zunge / Xerostomie & $\mathrm{p}<, 05468$ (Tendenz) \\
\hline soortypische Beläge Schleimhaut / Xerostomie & $\mathrm{p}<, 03851$ \\
\hline anderweitig belegte Zunge / Xerostomie & $\mathrm{p}<, 02499$ \\
\hline anderweitig belegte Zunge / Dysgeusie & $\mathrm{p}<, 06506$ (Tendenz) \\
\hline anderweitig belegte Schleimhaut / Xerostomie & $\mathrm{p}<, 00502$ \\
\hline
\end{tabular}

Tabelle 21: Korrelationen der Merkmale

Bei der Korrelation der Merkmale „Pilzbefall“ und „Xerostomie“ kann davon ausgegangen werden, dass bei Vorhandensein einer Mykose in der Mundhöhle mit einer Wahrscheinlichkeit von $87,50 \%$ ebenfalls eine Xerostomie besteht. Wenn eine Xerostomie angegeben wird, dann liegt die Wahrscheinlichkeit bei 75,90\%, dass auch ein Pilzbefund zu erwarten ist. (Tabelle 22) [Ausführliche statistische Auswertung siehe Anhang] 


\begin{tabular}{|c|c|c|c|}
\hline$p<, 02766$ & Xerostomie ja & Xerostomie nein & Gesamt \\
\hline Pilze ja & 63 & 9 & 72 \\
\hline Pilze nein & 20 & 9 & 29 \\
\hline Gesamt & 83 & 18 & 101 \\
\hline
\end{tabular}

Tabelle 22: Korrelation Pilzbefall / Xerostomie

Bei der Korrelation der Merkmale „Pilzbefall“ und „Dysgeusie“ kann davon ausgegangen werden, dass bei Vorhandensein einer Mykose in der Mundhöhle mit einer Wahrscheinlichkeit von 73,61\% ebenfalls eine Dysgeusie besteht. Wenn eine Dysgeusie angegeben wird, dann liegt die Wahrscheinlichkeit bei 77,94\%, dass auch ein Pilzbefund zu erwarten ist (Tabelle 23) [Ausführliche statistische Auswertung siehe Anhang].

\begin{tabular}{|c|c|c|c|}
\hline$p<, 03386$ & Dysgeusie ja & Dysgeusie nein & Gesamt \\
\hline Pilze ja & 53 & 19 & 72 \\
\hline Pilze nein & 15 & 14 & 29 \\
\hline Gesamt & 68 & 33 & 101 \\
\hline
\end{tabular}

Tabelle 23: Korrelation Pilzbefall / Dysgeusie

Bei der Korrelation der Merkmale „Abweichung von der physiologischen Mundflora“ und „Dysgeusie“ kann davon ausgegangen werden, dass bei einer abweichenden Besiedelung der Mundhöhle mit einer Wahrscheinlichkeit von 82,35\% ebenfalls eine Dysgeusie besteht. Wenn eine Dysgeusie angegeben wird, dann liegt die Wahrscheinlichkeit bei 41,18\%, dass auch eine abweichende Besiedelung der Mundhöhle besteht (Tabelle 24) [Ausführliche statistische Auswertung siehe Anhang].

\begin{tabular}{|c|c|c|c|}
\hline$p<, 02181$ & Dysgeusie ja & Dysgeusie nein & Gesamt \\
\hline abweichende Besiedelung ja & 28 & 6 & 34 \\
\hline abweichende Besiedelung nein & 40 & 27 & 67 \\
\hline Gesamt & 68 & 33 & 101 \\
\hline
\end{tabular}

Tabelle 24: Korrelation Abweichung von der physiologischen Mundflora / Dysgeusie

Bei der Korrelation der Merkmale „soortypische Beläge auf der Zunge“ und „Xerostomie“ kann davon ausgegangen werden, dass bei Vorhandensein von soortypischen Belägen auf der Zunge mit einer Wahrscheinlichkeit von 95,69\% ebenfalls eine Xerostomie besteht. Wenn eine Xerostomie angegeben wird, dann liegt die Wahrscheinlichkeit bei 26,51\%, dass auch soortypische Beläge auf der Zunge zu finden sind (Tabelle 25) [Ausführliche statistische Auswertung siehe Anhang]. 


\begin{tabular}{|c|c|c|c|}
\hline$p<, 05468$ & Xerostomie ja & Xerostomie nein & Gesamt \\
\hline soortypische Beläge Zunge ja & 22 & 1 & 23 \\
\hline soortypische Beläge Zunge nein & 61 & 17 & 78 \\
\hline Gesamt & 83 & 18 & 101 \\
\hline
\end{tabular}

Tabelle 25: Korrelation soortypische Beläge auf der Zunge / Xerostomie

Bei der Korrelation der Merkmale „soortypische Beläge auf der Schleimhaut“ und „Xerostomie“ kann davon ausgegangen werden, dass bei Vorhandensein von soortypischen Belägen auf der Schleimhaut mit einer Wahrscheinlichkeit von 93,75\% ebenfalls eine Xerostomie besteht. Wenn eine Xerostomie angegeben wird, dann liegt die Wahrscheinlichkeit bei 36,14\%, dass auch soortypische Beläge auf der Schleimhaut zu finden sind (Tabelle 26) [Ausführliche statistische Auswertung siehe Anhang].

\begin{tabular}{|c|c|c|c|}
\hline$p<, 03851$ & Xerostomie ja & Xerostomie nein & Gesamt \\
\hline soortypische Beläge Schleimhaut ja & 30 & 2 & 32 \\
\hline soortypische Beläge Schleimhaut nein & 53 & 16 & 69 \\
\hline Gesamt & 83 & 18 & 101 \\
\hline
\end{tabular}

Tabelle 26: Korrelation soortypische Beläge auf der Schleimhaut / Xerostomie

Bei der Korrelation der Merkmale „anderweitige Beläge auf der Zunge“ und „Xerostomie“ kann davon ausgegangen werden, dass bei Vorhandensein von anderweitigen Belägen auf der Zunge mit einer Wahrscheinlichkeit von $86,42 \%$ ebenfalls eine Xerostomie besteht. Wenn eine Xerostomie angegeben wird, dann liegt die Wahrscheinlichkeit bei 84,34\%, dass auch anderweitige Beläge auf der Zunge zu finden sind (Tabelle 27) [Ausführliche statistische Auswertung siehe Anhang].

\begin{tabular}{|c|c|c|c|}
\hline$p<, 02499$ & Xerostomie ja & Xerostomie nein & Gesamt \\
\hline anderweitige Beläge Zunge ja & 70 & 11 & 81 \\
\hline anderweitige Beläge Zunge nein & 13 & 7 & 20 \\
\hline Gesamt & 83 & 18 & 101 \\
\hline
\end{tabular}

Tabelle 27: Korrelation anderweitige Beläge auf der Zunge / Xerostomie

Bei der Korrelation der Merkmale ,anderweitige Beläge auf der Zunge“ und „Dysgeusie“ kann davon ausgegangen werden, dass bei Vorhandensein von anderweitigen Belägen auf der Zunge mit einer Wahrscheinlichkeit von 71,60\% ebenfalls eine Dysgeusie besteht. Wenn eine Dysgeusie angegeben wird, dann liegt die Wahrscheinlichkeit bei 85,29\%, dass auch 
anderweitige. Beläge auf der Zunge zu finden sind (Tabelle 28) [Ausführliche statistische Auswertung siehe Anhang].

\begin{tabular}{|c|c|c|c|}
\hline$p<, 06506$ & Dysgeusie ja & Dysgeusie nein & Gesamt \\
\hline anderweitige Beläge Zunge ja & 58 & 23 & 81 \\
\hline anderweitige Beläge Zunge nein & 10 & 10 & 20 \\
\hline Gesamt & 68 & 33 & 101 \\
\hline
\end{tabular}

Tabelle 28: Korrelation anderweitige Beläge auf der Zunge / Dysgeusie

Bei der Korrelation der Merkmale ,anderweitige Beläge auf der Schleimhaut“ und „Xerostomie“ kann davon ausgegangen werden, dass bei Vorhandensein von anderweitigen Belägen auf der Schleimhaut mit einer Wahrscheinlichkeit von 90,48\% ebenfalls eine Xerostomie besteht. Wenn eine Xerostomie angegeben wird, dann liegt die Wahrscheinlichkeit bei $68,67 \%$, dass auch anderweitige Beläge auf der Schleimhaut zu finden sind.(Tabelle 29) [Ausführliche statistische Auswertung siehe Anhang].

\begin{tabular}{|c|c|c|c|}
\hline$p<, 00502$ & Xerostomie ja & Xerostomie nein & Gesamt \\
\hline anderweitige Beläge Schleimhaut ja & 57 & 6 & 63 \\
\hline anderweitige Beläge Schleimhaut nein & 26 & 12 & 38 \\
\hline Gesamt & 83 & 18 & 101 \\
\hline
\end{tabular}

Tabelle 29: Korrelation anderweitige Beläge auf der Schleimhaut / Xerostomie

\subsection{Zusammenhang von klinisch sichtbaren Belägen und mikrobiologischen Pilzbefunden}

\begin{tabular}{|c|c|}
\hline Merkmale & Signifikanzniveau \\
\hline Pilze / soortypische Beläge auf der Zunge & $p<, 05875$ \\
\hline Pilze / soortypische Beläge auf der Schleimhaut & $p<, 01418$ \\
\hline Pilze / anderweitige Beläge auf der Zunge & $p<, 21281$ \\
\hline Pilze / anderweitige Beläge auf der Schleimhaut & $p<, 00570$ \\
\hline
\end{tabular}

Tabelle 30: Korrelation von Belägen und Pilznachweis

Bei der Verknüpfung der klinischen Befunde (Beläge) und den mikrobiologischen Ergebnissen (Pilze) (Tabelle 30) wurden zwei statistisch signifikante Korrelationen (Pilze / soortypische Beläge auf der Schleimhaut $\mathrm{p}<, 01418$; Pilze / anderweitige Beläge auf der Schleimhaut $\mathrm{p}<, 00570$ ) festgestellt.

Bei der Verknüpfung der Merkmale Pilze / soortypische Beläge auf der Zunge ist von einer statistischen Tendenz $(\mathrm{p}<, 05875)$ auszugehen. 


\subsection{Clusterbildung}

Im Rahmen der weiteren Datenanalyse können Cluster gebildet werden, welche unter Anderem das Vorhandensein von Belägen in der Mundhöhle und auf der Zunge in Zusammenhang mit dem gleichzeitigen Auftreten von Pilzen und Dysgeusie bringen.

In der Tabelle 31 wurden Patienten mit gleichzeitigem Befund von Pilzen und Dysgeusie zusammengefasst $(\mathrm{n}=53)$.

Innerhalb dieser Gruppe ist auffällig, dass bei 86,79\% der Patienten auch anderweitige Beläge auf der Zunge sowie 69,81\% anderweitige Beläge auf der Schleimhaut vorhanden waren. Auffällig ist, dass die soortypischen Beläge auf der Schleimhaut mit 37,74\% sowie soortypische Beläge auf der Zunge mit 28,3\% deutlich geringer ausgeprägt sind als anderweitige Beläge.

\begin{tabular}{|c|c|c|c|c|}
\hline Pilze / Dysgeusie & $\begin{array}{c}\text { anderweitige Beläge } \\
\text { auf der Zunge }\end{array}$ & $\begin{array}{c}\text { anderweitige Beläge } \\
\text { auf der Schleimhaut }\end{array}$ & $\begin{array}{c}\text { soortypische Beläge } \\
\text { auf Schleimhaut }\end{array}$ & $\begin{array}{c}\text { soortypische Beläge } \\
\text { auf der Zunge }\end{array}$ \\
\hline \multirow{2}{*}{53} & Ja $46(86,79 \%)$ & Ja $37(69,81 \%)$ & Ja $20(37,74 \%)$ & Ja 15 $(28,3 \%)$ \\
\cline { 2 - 5 } & Nein $7(13,21 \%)$ & Nein $16(30,19 \%)$ & Nein $33(62,26 \%)$ & Nein $38(71,7 \%)$ \\
\hline
\end{tabular}

Tabelle 31: Gruppe Pilzinfektion \& Dysgeusie / Beläge

Auch bei gleichzeitigem Vorhandensein von Pilzen und Xerostomie $(n=63)$ ist eine erhöhtes Auftreten von Geschmacksstörungen zu beobachten. Insgesamt 48 (76,19\%) Patienten gaben eine Dysgeusie an bei gleichzeitigem Vorhandensein von Pilzen und Xerostomie (Tabelle 32).

\begin{tabular}{|c|c|}
\hline Pilze / Xerostomie & Dysgeusie \\
\hline \multirow{2}{*}{63} & Ja 48 $(76,19 \%)$ \\
\cline { 2 - 2 } & Nein $15(23,81 \%)$ \\
\hline
\end{tabular}

Tabelle 32: Gruppe Pilze \& Xerostomie / Dysgeusie

In der zusammengefassten Gruppe von Patienten, die sowohl eine abweichende bakterielle Besiedelung als auch eine Dysgeusie hatten $(\mathrm{n}=28)$, ist $\mathrm{zu}$ sehen, dass eine überdurchschnittlich hohe Zahl, nämlich 24 (85,71\%) dieser Patienten, auch eine Xerostomie angegeben hatten (Tabelle 33).

\begin{tabular}{|c|c|c|}
\hline Abweichende bakterielle Besiedlung / Dysgeusie & Xerostomie & Pilze \\
\hline \multirow{2}{*}{28} & Ja 24 (85,71\%) & Ja 22 (78,57\%) \\
\cline { 2 - 3 } & Nein 4 (14,29\%) & Nein $6(21,42 \%)$ \\
\hline
\end{tabular}

Tabelle 33: Gruppe abweichende bakterielle Besiedlung \& Dysgeusie / Xerostomie / Pilze 
In der zusammengefassten Gruppe der Patienten mit einer Herpes-simplex-Infektion sowie Dysgeusie $(n=12)$ sind in vermehrtem Ausmaß Xerostomie $(11$ Patienten $=91,6 \%)$ und anderweitige Beläge auf der Zunge (10 Patienten = 83,33\%) anzutreffen (Tabelle 34).

\begin{tabular}{|c|c|c|}
\hline HSV / Dysgeusie & Xerostomie & anderweitig belegte Zunge \\
\hline \multirow{2}{*}{12} & Ja $11(91,6 \%)$ & Ja $10(83,33 \%)$ \\
\cline { 2 - 3 } & Nein $1(8,4 \%)$ & Nein $2(16,67)$ \\
\hline
\end{tabular}

Tabelle 34: Gruppe HSV \& Dysgeusie / Xerostomie / anderweitig belegte Zunge

Bei einer Kombination von einer Herpes-simplex-Infektion sowie einer abweichenden bakteriellen Besiedelung ist eine hohe Anzahl von Patienten (acht $=72,72 \%)$ anzutreffen, die eine Dysgeusie angeben (Tabelle 35).

\begin{tabular}{|c|c|}
\hline HSV/ abweichende bakterielle Besiedlung & Dysgeusie \\
\hline \multirow{2}{*}{11} & Ja $8(72,72 \%)$ \\
\cline { 2 - 2 } & Nein 3 (27,27\%) \\
\hline
\end{tabular}

Tabelle 35: HSV \& abweichende bakterielle Besiedelung / Dysgeusie

Bei der Analyse der Daten ist weiterhin zu sehen, dass bei einer Gruppe von Patienten, bei denen sowohl HSV als auch Dysgeusie nachgewiesen wurde, anderweitig belegte Schleimhäute häufiger anzutreffen sind als soortypische Beläge (Tabelle 36).

\begin{tabular}{|c|c|c|c|}
\hline HSV / Dysgeusie & $\begin{array}{c}\text { anderweitige Beläge } \\
\text { auf der Schleimhaut }\end{array}$ & $\begin{array}{c}\text { soortypische Beläge } \\
\text { auf der Schleimhaut }\end{array}$ & $\begin{array}{c}\text { soortypische Beläge } \\
\text { auf der Zunge }\end{array}$ \\
\hline \multirow{2}{*}{12} & Ja $7(58,33 \%)$ & Ja $5(41,66 \%)$ & Ja 2 (16,67\%) \\
\cline { 2 - 4 } & Nein 5 (41,66\%) & Nein $7(58,33 \%)$ & Nein $10(83,33 \%)$ \\
\hline
\end{tabular}

Tabelle 36: Gruppe HSV \& Dysgeusie / anderweitige Beläge Schleimhaut / soortypische Beläge Schleimhaut / soortypische Beläge Zunge 


\subsection{Subjektives Empfinden im Verhältnis zu klinischen und mikrobiologischen Befunden}

Die Korrelation des subjektiven Befindens der Patienten mit objektivierbaren klinischen Befunden der Mundhöhle und mikrobiologischen Untersuchungsergebnissen stellt eines der wesentlichen Anliegen dieser Studie dar (Tabelle 37).

Das Erfassen des subjektiven Befindens des Patienten wurde anhand des Fragebogens (Anhang) durchgeführt. Die am häufigsten genannten Probleme sind Xerostomie, welche von 83 Patienten, und Dysgeusie, die von 68 Patienten angegeben worden sind.

Weiterhin geben 29 Patienten Schluckbeschwerden und 26 Patienten Mundgeruch an. Zahnschmerzen wurden insgesamt in nur vier Fällen angegeben.

Bei der klinischen Untersuchung der Mundhöhle waren Beläge unterschiedlichster Art am auffälligsten. Die Unterscheidung zwischen soortypischen Belägen und anderweitig belegter Zunge bzw. Schleimhaut gestaltete sich in Anbetracht der kurzen Untersuchungszeit und fließender Übergänge beider Typen als sehr schwierig.

Im Bereich der Zunge wurden bei 81 Patienten anderweitige Beläge und bei 23 Patienten soortypische Beläge gefunden. Im Bereich der Schleimhaut der Mundhöhle (Vestibulum, Mundboden und Gaumen) waren bei 63 Patienten anderweitige Beläge und bei 32 Patienten soortypische Beläge zu sehen.

Weiterhin konnten bei 62 Patienten eine gerötete Gingiva, bei 19 Patienten eine geschwollene (hyperplasische) Gingiva sowie fünf gingivale Hämatome beobachtet werden. Bei 15 Patienten wurden Druckstellen und bei 14 Patienten eine Aphthe diagnostiziert.

Im Rahmen der mikrobiologischen Untersuchung war ein hoher Anteil von Mykosen mit 72 nachgewiesenen Fällen besonders auffällig (Tabelle 20). Eine abweichende bakterielle Besiedelung war in 34 Fällen $\mathrm{zu}$ beobachten, wobei bei drei Patienten ein methicillinresistenter Staph. aureus (MRSA) sowie ein vancomycinresistenter Enterococcus (VRE) detektiert wurde.

Bei der HSV-PCR der Rachenspüllösung waren 19 Befunde positiv (Tabelle 19). 


\begin{tabular}{|c|c|c|c|c|c|c|}
\hline$n=101$ & Schmerz & $\begin{array}{l}\text { Xero- } \\
\text { stomie }\end{array}$ & $\begin{array}{l}\text { Mund- } \\
\text { geruch }\end{array}$ & $\begin{array}{l}\text { Dys- } \\
\text { phagie }\end{array}$ & Dysgeusie & Gesamt \\
\hline $\begin{array}{c}\text { soortypische Beläge } \\
\text { (Zunge) }\end{array}$ & 2 & 22 & 10 & 7 & 17 & 23 \\
\hline $\begin{array}{c}\text { anderweitige Beläge } \\
\text { (Zunge) }\end{array}$ & 4 & 70 & 21 & 26 & 58 & 81 \\
\hline $\begin{array}{c}\text { soortypische Beläge } \\
\text { (Schleimhaut der } \\
\text { Mundhöhle) }\end{array}$ & 2 & 30 & 12 & 9 & 23 & 32 \\
\hline $\begin{array}{c}\text { anderweitige Beläge } \\
\text { (Schleimhaut der } \\
\text { Mundhöhle) }\end{array}$ & 3 & 57 & 17 & 22 & 45 & 63 \\
\hline Gingiva gerötet & 3 & 54 & 20 & 18 & 44 & 62 \\
\hline Gingiva geschwollen & 0 & 16 & 6 & 8 & 15 & 19 \\
\hline Gingivales Hämatom & 0 & 4 & 2 & 1 & 4 & 5 \\
\hline Druckstelle & 0 & 14 & 5 & 3 & 10 & 15 \\
\hline Aphthe & 1 & 12 & 8 & 5 & 12 & 14 \\
\hline Gingiva normal & 1 & 27 & 5 & 10 & 22 & 36 \\
\hline Schleimhaut normal & 1 & 22 & 4 & 8 & 20 & 32 \\
\hline HSV PCR + & 2 & 17 & 8 & 4 & 14 & 19 \\
\hline Pilze + & 2 & 63 & 18 & 22 & 53 & 72 \\
\hline abw. bakt. Besiedlung & 1 & 30 & 13 & 13 & 28 & 34 \\
\hline multiresist. Keim & 0 & 4 & 2 & 1 & 4 & 4 \\
\hline Gesamt & 4 & 83 & 26 & 29 & 68 & \\
\hline
\end{tabular}

Tabelle 37: Subjektive Symptomwahrnehmung in Korrelation zu klinischen und mikrobiologischen Befunden 


\section{Diskussion}

Bei Patienten unter palliativmedizinischer Betreuung, treten häufig enorale Symptome auf, welche das Wohlbefinden sowie die Lebensqualität des Patienten erheblich beeinträchtigen können.

Mundtrockenheit und Geschmacksstörungen waren die am häufigsten angegebenen Symptome dieser repräsentativen Gruppe von Palliativpatienten einer Abteilung, ungeachtet anderer klinischer und mikrobiologischer Befunde. Die Prävalenz dieser Symptome stellt sich im Vergleich zu anderen epidemiologischen Studien, bei denen die Symptome von den untersuchenden Personen (incl. Ärzten und Pflegepersonal) eingeschätzt worden waren, als deutlich höher dar (Radbruch et al. 2003). Insofern kann geschlussfolgert werden, dass die Methode der Datenerhebung, in dieser Studie gekennzeichnet durch direkte Befragung der Patienten, erheblichen Einfluss auf die Ermittlung subjektiv relevanter Daten hat, und dass die Prävalenz von Symptomen der Mundhöhle in vorangehenden epidemiologischen Untersuchungen eher unterschätzt wurde.

Soortypische und/oder anderweitige Beläge waren die häufigsten klinischen Befunde ungeachtet von anderen berichteten Symptomen oder mikrobiologischen Ergebnissen. Insoweit unterschieden sich die klinischen Befunde bereits in Bezug auf diesen Aspekt deutlich von denen onkologischer Patienten unter Chemo- / Strahlenherapie in anderen Studien, bei denen Mucositis als klinischer Befund in bis zu 40\% aufgeführt wird (Wiseman 2006, Naidu et al. 2004). Bereits hier wird deutlich, dass das untersuchte Patientenkollektiv einer Palliativstation sich wesentlich von anderen Kollektiven fortgeschritten erkrankter Patienten, die eher in onkologischen Therapiekonzepten behandelt werden, unterscheidet.

Eine Vielzahl an Faktoren wie soortypische Beläge, Pilze, Herpes-simplex-Viren, Anticholinergika, Benzodiazepine und Opioide ging einher mit dem Empfinden von Mundtrockenheit, weniger oft mit Geschmacksstörungen. Aufgrund dieses eher stereotypen Symptommusters kann die Schlussfolgerung gezogen werden, dass eine einseitige Kausalzuschreibung, die z.B. das Symptom Mundtrockenheit monokausal auf den Gebrauch von Opioiden zuschreibt, nicht zulässig ist. Für die Palliativmedizin bedeutet dieses Resultat eine Bestätigung eines klinischen Behandlungsansatzes, der weniger diagnose- oder befundorientiert, als eher symptom- und lebensqualitätsorientiert vorgeht. 
Signifikante Korrelationen ergaben sich (unter der methodischen Limitation der post-hocBerechnung) lediglich bei den Merkmalen Xerostomie, Geschmacksstörungen und soortypischen bzw. anderweitigen Belägen und Hefen. In Hinblick auf Bonferroni-adjustierte Signifikanzlevel erwies sich lediglich die Korrelation zwischen Mundtrockenheit und Plaques der Mundschleimhaut als signifikant.

Auch vor dem Hintergrund des eher stereotypen Symptommusters, welches dominiert wird von Mundtrockenheit und Geschmacksstörungen, spielt der mikrobiologische Nachweis von Candida daher eine auffällig große Rolle, die in Hinblick auf die Candida-Prävalenz in der gesunden, arbeitenden Vergleichsgruppe in der gefundenen Ausprägung nicht zu erwarten gewesen war.

In Anbetracht des im Durchschnitt eher unauffälligen dentalen Zustandes des untersuchten Patientenkollektives scheint ein dentaler Co-Faktor bei der Entstehung oraler Symptome eher unwahrscheinlich.

Trotz einer hier angetroffenen teilweise unauffälligen prothetischen Versorgung ist deren Rolle in Bezug auf das damit veränderte Ökosystem der Mundhöhle nicht zu vernachlässigen (Theilade E., Theilade J. 1985). Bei Candida spielt der sog. Dimorphismus eine besondere Rolle. Auf eine Veränderung der Lebensbedingungen der Pilze z.B. im Zusammenhang mit schlecht sitzenden Prothesen folgt die Umwandlung der klinisch inapparenten Saprophyten (die ebenfalls bei Gesunden anzutreffen sind) in eine parasitäre myzeliale Phase, bei der die bekannten klinischen Symptome und Befunde in Erscheinung treten können (Jung 1995). Besonders bei älteren und stark immungeschwächten Patienten ist die Invasivität von Candida albicans erleichtert (Pschyrembel 1990). Treten noch weitere Faktoren hinzu, wie intensivmedizinische Therapien oder operative Eingriffe sowie vorausgegangene oder bestehende antibiotische Therapien, erhöht sich die Häufigkeit opportunistischer (teils systemischer) Mykosen (Hedderwick, Kauffman 1997).

Diese Mechanismen können zu der hier mikrobiologisch nachgewiesenen hohen Prävalenz von Candidosen in pathophysiologischer Hinsicht beitragen. Auffällig ist zudem die damit signifikante Korrelation mit offenkundigen Belägen (z.B. soortypische Beläge auf der Schleimhaut / Pilze). Hiernach kann man mit einer durchschnittlichen Wahrscheinlichkeit von $82 \%$ bei Vorhandensein von Belägen in der Mundhöhle, im Bereich der Schleimhäute und der Zunge von einer Mykose ausgehen. 
Die gefundenen Beläge der Mundhöhle zeigten sehr unterschiedliche Erscheinungsbilder. Dieses kann von unterschiedlichen Faktoren wie zuvor eingenommenen Medikamenten, Mundhygiene, Speichelsekretion und Nahrungsaufnahme abhängen. Eine rein visuelle Bewertung der ohnehin schwierig zu beurteilenden Morphologie der Beläge erwies sich dennoch als aussagekräftig, da in der vorliegenden Untersuchung eine gute Korrelation mit den Resultaten der mikrobiologischen Untersuchungen gefunden wurde (siehe Tabelle 30).

Etwa 1/5 der Patienten wurde mittels PCR positiv auf Herpes-simplex-Virus in der Rachenspülung getestet. Verglichen mit der Gesamtzahl der Untersuchungen sind die 19 positiven Fälle mit relativ geringem Konzentrationsnachweis der Viren nicht sehr auffällig (Tabelle 19). Das Symptomspektrum der positiv Getesteten unterschied sich nicht von dem anderer Untergruppen von Patienten; insbesondere beschrieben nicht alle Patienten mit positivem enoralen HSV-Nachweis orale Schmerzen, wie man hätte vielleicht erwarten können. Lediglich 50\% der vier Patienten, welche Schmerzen im Mund und Rachenraum angaben, hatten einen positiven HSV-Titer. Deshalb wäre ein empirisch therapeutischer Ansatz mit antiviralen Substanzen ohne nachgewiesene Virusinfektion nicht zu unterstützen.

Die klinische Relevanz einiger Befunde, insbesondere mikrobiologischer Befunde, verbleibt jedoch unklar:

- Bei vier Patienten wurden als Zufallsbefunde multiresistente Keime wie MRSA oder VRE festgestellt. Dies regt auch zu einer weiteren Betrachtung von Hygienestandards oder der Isolationspolitik an. Zwar gibt es einige europäische Krankenhäuser, die eine generelle mikrobiologische Untersuchung aller stationär aufgenommenen Patienten routinemäßig durchführen jedoch scheint ein solches Vorgehen in Deutschland angesichts der enormen Kosten derzeit nicht realisierbar. Zudem könnten restriktive Isolationsstandards auch mit den therapiebezogenen Prioritäten der Palliativbehandlung in Konflikt kommen.

- Bei 11 Patienten wurden mehrere, teils obligat pathogene Keime gefunden. Dies rückt Fragen nach den Kriterien der Kolonisation bzw. der Infektion in den Blickpunkt, und bedarf weiterer Klärung.

- 10 Patienten wiesen zwei verschiedene Candida-Stämme auf. Dies wirft die Frage nach der Relevanz von Resistenzen gegen Antimykotika (z.B. Azole) auf, auch wenn in der vorliegenden Untersuchung keine Resistenzprüfungen gegenüber Antimykotika durchgeführt wurden. 
- Das mikrobiologische Kriterium einer abweichenden bakteriellen Besiedlung, welches bei 34 Patienten gegeben war, erwies sich hinsichtlich der Prävalenz und den Hauptkeimen als mit einer Referenzgruppe vergleichbar.

Eine methodische Limitation der mikrobiologischen Untersuchungen bestand in der Abstrichanalyse, bei der anaerobe Keime nicht detektiert wurden. Die Daten der Kontrollgruppe (interne Referenzgruppe), welche uns kollegialerweise von der Abteilung Mikrobiologie der Universität Göttingen zur Verfügung gestellt wurden, können zudem aufgrund der ungleichen Altersverteilung nur sehr begrenzt auf das hier untersuchte Patientenkollektiv übertragen werden; ein Beitrag des Alters auf die gefundenen Veränderungen kann nicht ausgeschlossen werden. Aus den Antworten der Studienteilnehmer $\mathrm{zu}$ den Fragen zur Symptomintensität, die in etwa $1 / 4$ aller Fälle sowohl Symptome beschrieben als auch eine Intensität von NRS $=0$ angaben, muss geschlussfolgert werden, dass diese Fragen nicht exakt genug differenziert werden konnten, so dass Fragen zum Grading der Symptome verbleiben.

Es gibt nur wenige vorausgehende Untersuchungen über Palliativpatienten, welche ihr Augenmerk ebenfalls auf Symptome der Mundhöhle (Bagg, et al. 2003) oder Prävalenzen von oralen Infektionen/abweichende Besiedelungen (Sweeney, Bagg 2000) richten. Es gaben 82\% der 101 untersuchten Patienten in unserer Studie eine Mundtrockenheit an. In einer vergleichbaren Studie (Jobbins et al. 1992) gaben von 197 untersuchten Patienten, ebenfalls 77\% eine Mundtrockenheit an. In einer weiteren vergleichbaren Studie (Bagg et al.2003), wurden 207 Patienten auf Pilzinfektionen mikrobiologisch untersucht. Bei diesen 207 untersuchten Patienten wurden 139 (67\%) positiv auf Hefen getestet. Von diesen 139 positiv getesteten Patienten hatten 91 (65\%) eine Pilzart, 41 (30\%) zwei Pilzarten und 7 (5\%) Patienten 3 Pilzarten. Als Vergleich wurden in unserer Studie insgesamt 72 (71\%) positiv auf Hefen getestet. Von diesen 72 Patienten hatten 62 (61\%) nur eine Hefeart und 10 (10\%) zwei Hefearten. Alle Voruntersuchungen zeigen eine hohe Prävalenz von Xerostomie und Candidosen als gemeinsames augenfälliges Merkmal. Dysgeusie stellt eines der weiteren Hauptsymptome dar (in unserer Studie mit 67\% angegeben). In früheren Studien (Twycross, Lack 1986; Bovio et al. 2008) wird die Prävalenz dieses Symptoms zwischen 25\% - 50\% angegeben. Als Ursache werden Strahlentherapie, Chemotherapie, Zinkmangel, Xerostomie und medikamentös bedingte Störungen angegeben. Ein beschriebener Ansatz zur Linderung von Dysgeusie ist neben der Zufuhr von Zink (Mossman 1986), auch der Zusatz von 
Mononatriumglutamat zur der täglichen Nahrung, um eine Geschmacksverstärkung zu erzielen.

Eine erst kürzlich durchgeführte Studie aus Norwegen (Wilberg 2009) ergab Symptomhäufigkeiten und klinische Befunde, die denen unseres Patientenkollektivs ähnelten, abgesehen von der dort beschriebenen höheren Prävalenz enoraler Schmerzen, welche auf begleitende onkologische Therapien und damit assoziierter Mukositis zurückgeführt werden könnten.

In diesen Voruntersuchungen stand eine Verknüpfung zwischen lokalen, subjektiven Symptomen und klinisch mikrobiologischen befunden nicht im Vordergrund.

Aus den genannten Resultaten ergibt sich eine Reihe zukünftiger wissenschaftlicher Fragestellungen. So liegt es nahe, z.B. in Interventionsstudien, Pilzinfektionen in Hinblick auf eine verbesserte orale Symptomkontrolle zu behandeln, oder verschiedene Symptome der Mundhöhle wie Xerostomie und Geschmacksstörungen mit Antimykotika wie Nystatin, Amphotericin oder Azolen empirisch zu behandeln. Auch longitudinale Untersuchungen, die Aufschluss über die zeitlichen Veränderungen eines bestätigten subklinischen mikrobiologischen Befundes eventuell hin $\mathrm{zu}$ einer offensichtlichen soortypischen Belagbildung bzw. symptomatischen Infektion, oder Vergleiche der Gruppe von Palliativpatienten mit anderen Gruppen, die en erhöhtes Candidoserisiko aufweisen, wie Intensivpatienten, geriatrische Patienten oder Pflegeheimbewohner, stehen aus.

\section{Schlussfolgerung}

In dieser prospektiven Pilotuntersuchung an einer repräsentativen Kohorte von Palliativpatienten konnten Symptome der Mundhöhle als relevantes (und zuvor womöglich unterschätztes) palliativmedizinisches Problem identifiziert werden. Eine Vielzahl klinischer und mikrobiologischer Faktoren scheint zur Symptombildung beizutragen; eine besondere Rolle spielen Beläge und der mikrobiologische Nachweis einer Candidose. Solange zu empirischen antimykotischen Interventionen keine weiterführenden Daten existieren, scheint eine Priorisierung symptomorientierter Therapieansätze vor einem befund- oder laborgerichteten Therapievorgehen gerechtfertigt.

In Hinblick auf eine mögliche Erweiterung der therapeutischen Optionen in der Palliativmedizin trägt die vorliegende Untersuchung somit in sinnhafter Ergänzung der 
wenigen vorangegangenen Untersuchungen zu einem besseren Verständnis der klinischen enoralen Probleme bei Palliativpatienten bei.

\section{Zusammenfassung}

In der vorliegenden Studie wurde der Frage nachgegangen, ob sich eine enorale Beschwerdesymptomatik auf eine Veränderung der normalen Mundflora oder auf klinisch manifeste Befunde zurückführen lässt, und inwieweit nachgewiesene klinische oder mikrobiologische Veränderungen der Mundhöhle Auswirkungen auf das Wohlbefinden von Palliativpatienten haben.

Um diese Fragen zu klären, wurden 101 Patienten der Palliativstation des Universitätsklinikums Göttingen in einem explorativen Ansatz im Sinne einer Pilotstudie untersucht. Dabei wurden im Rahmen der Befragung die subjektiven Symptome sowie klinische Befunde der Mundhöhle erfasst. Des Weiteren wurden zwecks mikrobiologischer Untersuchung eine Rachenspülung und ein Abstrich in der Mundhöhle durchgeführt.

$\mathrm{Zu}$ den am häufigsten angegebenen subjektiven Missempfindungen gehörten Mundtrockenheit und Geschmacksstörung. Zu den auffälligsten klinischen Befunden zählten Beläge auf der Mundschleimhaut sowie auf der Zunge.

Bei den mikrobiologischen Untersuchungen war die hohe Zahl der Mykosen (72 Befunde) sehr auffällig. Eine abweichende bakterielle Besiedelung der Mundhöhle konnte bei 34 Patienten festgestellt werden, wobei vier Patienten als Zufallsbefunde multiresistente Keime wie MRSA und VRE aufwiesen.

Bei der statistischen Korrelation der verschiedenen Merkmale war das Auftreten von Pilzen und Dysgeusie $(\mathrm{p}<, 03386)$ sowie Pilzen und Xerostomie $(\mathrm{p}<, 02766)$ signifikant. Weiterhin war eine Signifikanz bei der Korrelation anderweitiger Schleimhautbeläge und dem Symptom Mundtrockenheit zu erkennen ( $\mathrm{p}<, 00502)$. Auch im Bezug auf abweichende Besiedelung der Mundhöhle und Dysgeusie konnte eine statistische Signifikanz $(p<, 02181)$ festgestellt werden. Eingedenk der hohen Fehlerwahrscheinlichkeit des multiplen Testens konnte ein Bonferoni- 
adjustierter Signifikanzlevel lediglich für die Korrelation von Mundtrockenheit und Belägen der Mundhöhle gefunden werden.

Das nachgewiesene bakterielle Spektrum innerhalb der Untersuchungsgruppe war mit dem Spektrum der Referenzgruppe vergleichbar. Dies führte $\mathrm{zu}$ der Annahme, dass eine Fehlbesiedelung bzw. eine abweichende Besiedelung der Mundhöhle bei Patienten der Palliativstation nicht eindeutig zu belegen ist. Die Untersuchung der Rachenspüllösung mittels PCR wies bei 19 Patienten einen positiven HSV1-Befund auf, jedoch konnte keine statistisch signifikante Korrelation mit subjektiven Symptomen hergestellt werden.

Im Rahmen dieser Studie konnten Symptome der Mundhöhle als relevantes palliativmedizinisches Problem identifiziert werden. Als weiteres, zuvor womöglich unterschätztes mikrobiologisches Problem in der Palliativmedizin stellten sich sowohl Mykosen in der mikrobiologischen Untersuchung als auch Beläge der Mundhöhle in der klinischen Untersuchung dar, welche mit einer hohen Wahrscheinlichkeit (82\%) mit dem Nachweis von Candida in Verbindung zu bringen waren.

Das Hauptaugenmerk bisheriger Studien lag eher im Bereich der Prävalenz und Behandlung von Mukositiden bei onkologischen Patienten im Rahmen der Tumortherapie (z.B. Radio-/ Chemo-Therapie); insofern bietet die vorliegende Arbeit wesentliche, neue Erkenntnisse, die der unmittelbaren klinischen Versorgung von Palliativpatienten zugute kommen. 


\section{Literaturverzeichnis}

Al-Zahrany MS, Bissada NF, Borawskit EA. (2003): Obesity and periodontal disease in young, middle-aged and older Adults. J Periodontol; 74(5): 610-615

Andrä A, Naumann G: Odontogene pyogene Infektion. Johann Ambrosius Barth, Leipzig 1971

Bagg J, Sweeney MP, Lewis MA, Jackson MS, Coleman D, Al MA, Baxter W, McEndrick S, McHugh S (2003): High prevalence of non-albicans yeasts and detection of anti-fungal resistance in the oral flora of patients with advanced cancer. Palliat Med; 17(6): 477-81

Bonica JJ, Loeser JD, Chapman CR, Fordyce WE: The management of pain. Lea \& Febiger, Philadelphia London 1990

Comroe JH, Forster RE, Dubois AB, Briscoe WA, Carlsen E: Die Lunge. Schattauer Stuttgart 1968

Fidler P, Loprinzi CL, O'Fallon JR, et al. (1996) : Prospective evaluation of a chamomille mouth wash for prevention of 5-FU-induced oral mucositis. Cancer; $\underline{77}, 522-525$

Bovio G, Montagna G, Bariani C, Baiardi P: Upper gastrointestinal symptoms in patientswith andvanced cancer: relationship to nutritional and performance status. Springer Berlin 2009

Haneke E: Zungen und Mundschleimhautbrennen. Hanser, München 1980

Hedderwick S, Kauffman CA (1997): Opportunistic fungal infections: superficial and systemic candidiasis. Geriatrics; 22: 50-4, 59

Hellwege KD: Die Praxis der zahmedizinischen Prophylaxe. Dr. Alfred Hüthig Verlag, Heidelberg 1984

Higginson IJ: Health care needs assessment: Palliative and terminal care. In: Stevens A, Raftery J. eds. Health care needs assessment. Wessex Institute of Public Health Medicine; Oxford 1997, 183-260

http://www.zungenhygiene.de

Husebo S, Klaschik E: Palliativmedizin - Grundlagen und Praxis 4. Auflage, Springer Medizinverlag, Berlin 2006

Jobbins J, Bagg J, Addy M, Newcombe RG, Finlay IG (1992): Oral and dental disease in terminally ill cancer patients. Br Med J; $\underline{304:} 1612$

Jung, E.: Dermatologie. 3. Aufl., Hippokrates, Stuttgart 1995 
Kayser F: Medizinische Mikrobiologie. 8. Aufl., Thieme, Stuttgart, New York 1993

Keefe DM, Schubert DM (2007): Updated clinical practice guidelines for the prevention and treatment of mucositis. Cancer; 109 (5): 820-31

Keller C (1994):Die kleinen Widersacher der Zahnärzte - orale Streptokokken. Phillip J; 11 : 526

Klaschik E:Medikamentöse Schmerztherapie bei Tumor-Patienten. Pallia Med Verlag, Bonn 1998

Klaschik E: Schmerztherapie und Symptomkontrolle in der Palliativmedizin. In: Husebø, S, Klaschik E. Palliativmedizin: Prakt. Einführung in Schmerztherapie, Ethik und Kommunikation. Springer Berlin / Heidelberg; 2000a, 167-262

Klaschik E: Was ist Palliativmedizin? In: Husebø S. Klaschick E. Palliativmedizin: Prakt. Einführung in die Schmerztherapie, Ethik und Kommunikation. Springer Berlin/Heidelberg; $2000 \mathrm{~b}, 2-4$

Lang B, Filippi A (2005): Halithosis Teil 2: Diagnostik und Therapie. zm. 95 (5); 50-56

Langlais RP, Miller CS: Mundschleimhauterkrankungen: Ein Farbatlas zur schnellen Blickdiagnose. Übers. Von Jepsen K, Urban und Schwarzenberg, München - Wien Baltimore 1994

Lehmann RR: Ökologie der Mundhöhle. Georg Thieme Verlag, Stuttgart New York 1991

Mombelli A (1994): Paradontal-Diagnostik. Zahnärztl Mitt; $\underline{84:} 1452$

Mossman KL (1986): Gustatory tissue injury in man: radiation dose response relationships and mechanisms of taste loss. Br J Cancer Suppl; 7 : 9-11

Müller-Lissner S (1992): Nebenwirkungen von Laxantien. Z Gastroenterol; 30: 418-427

Naidu MU, Ramana GV, Rani PU, Mohan IK, Suman A, Roy P (2004): Chemotherapyinduced and/or radiation therapy-induced oral mucositis - complicating the treatment of cancer. Neoplasia; $\underline{6(5)}$ : 423-31

Pschyrembel W: Klinisches Wörterbuch. 256. Auflage, de Gruyter, Berlin, New York 1990

Radbruch L, Sabatowski R, Loick G, Jonen-Thielemann I, Elsner F, Hörmann E (2000) : MIDOS - Validation of a minimal documentation system for palliative medicine. Schmerz; 14 (4): $231-239$

Radbruch L, Nauck F, Ostgathe C, Elsner F, Bausewein C, Fuchs M, Lindena G, Neuwöhner K, Schulenberg D (2003): What are the problems in palliative care? Results from a representative survey. Support Care Cancer; 11: 442-451

Ripamonti C, Fulfaro F: Taste disturbance. In: Oral care in advanced disease. Davies A, Finlay I., University Press, Oxford 2005 
Saadeh CE (2005): Chemotherapy- and radiotherapy-induced oral mucositis: review of preventive strategies and treatment. Pharmacotherapy; 25(4): 540-54

Saunders DC. Foreword. In: Doyle D, Hanks J, Macdonnald N: Oxford textbook of palliative medicine. Oxford University Press, Oxford 1997

Sweeney MP, Bagg J (2000): The mouth and palliative care. Am J Hosp Palliat Care; 17(2): 118-24

Sweeney MP, Bagg J, Baxter WP, Aitchison (1997): TC. Clinical trial of a mucincontaining oral spray for treatment of xerostomia in hospice patients. Palliat Med; 11(3): 22532

Theilade E, Theilade J (1985): Formation and ecology of plaque in different locations in the mouth. Scand J Dent Res, 93:90-95

Twycross R: Pain relief in advanced cancer. Churchill Livingstone, Edinburgh/ London 1994: $1-15$

Twycross RG, Lack SA: Taste change. In: Control of Alimentary Symptoms in Far Advanced Cancer. Churchill Livingstone,Edinburgh 1986 ; 57-65

Vetter Ch (2005): Mundgeruch, Schluckauf, Sodbrennen und Co.; zm 95(21): 84-88

Wilberg P, Hjermstad MJ, Ottesen S, Herlofson BB (2009): Oral care in advanced cancer - a neglected problem? Congress of the European Association of Palliative Care,; abstract \# $\mathrm{S} 152$

Wiseman M (2006): The treatment of oral problems in the palliative patient. J Can Dent Assoc; 72(5): 453-8

www.whocollab.od.mah.se/expl/orhdmft.html 
9. Anhang

9.1. Fragebogen

9.1.1.Patienteninformation

UNIVERSITÄTSMEDIZIN $=\mathbf{M G}$
GÖTTINGEN :

Universitätsmedizin Göttingen, 37099 Göttingen

ZARI Abt. Palliativmedizin Prof. Dr. med. Friedemann Nauck

Zentrum Anaesthesiologie, Rettungs- und Intensivmedizin Abteilung Palliativmedizin

Direktor: Prof. Dr. med. Friedemann Nauck

37099 Göttingen Briefpost Robert-Koch-Straße 40, 37075 Göttingen $055139-9528$

Palliativmedizin@med.uni-goettingen.de

\section{Patienteninformation}

Sehr geehrte Patientin, sehr geehrter Patient,

wir möchten Sie informieren über eine Untersuchung unserer Abteilung zum Thema

\section{Beschwerden und Befunde im Mund- und Rachenraum.}

In der palliativmedizinischen Behandlung und Begleitung die Beschwerden der Patienten und ihre Lebensqualität ganz im Vordergrund. Beschwerden im Mund und Rachenraum sind als häufiges Problem anzutreffen, und nicht alle therapeutischen Möglichkeiten führen tatsächlich zu einer Linderung der Beschwerden.

Um mögliche Beschwerden wie Schmerzen, Mundtrockenheit, Mundgeruch, Geschmacksveränderungen oder andere Probleme besser verstehen zu können, möchten wir Sie hierzu genauer befragen. Ein ausgebildeter Zahnarzt wird in einer ca. fünfminütigen Untersuchung (in Ihrem Zimmer) Zähne, Zahnfleisch und Mundschleimhaut untersuchen. Abschließend möchten wir einen Wattetupfer abstreichen und Sie um eine kurze Mundspülung bitten. Diese Proben werden in der Universitätsmedizin Göttingen auf eventuell vorhandene Bakterien und Herpesviren untersucht und anschließend vernichtet.

Die Untersuchung ist selbstverständlich freiwillig; bei Nichtteilnahme oder Widerruf entstehen Ihnen keinerlei Nachteile. Die Untersuchung ist zudem schmerzfrei und ohne gesundheitliche Risiken. Die Untersuchungsergebnisse werden in Bezug auf Ihren Namen unkenntlich gemacht und dann ausgewertet; nur innerhalb der Klinik kann eine persönliche Zuordnung erfolgen. Nach Abschluß der Auswertung werden alle Daten gelöscht.

Neben einem besseren Verständnis von der Entstehung möglicher Beschwerden erhoffen wir uns über diese Untersuchung erste Hinweise auf eine gezieltere und effektivere Behandlung. So kommt diese Untersuchung Ihnen und auch anderen Patienten zugute.

Mit herzlichem Dank für Ihre Mitwirkung,

Prof. Dr. Friedemann Nauck

Direktor der Abteilung Palliativmedizin 


\section{Einverständniserklärung}

Sehr geehrte Patientin, sehr geehrter Patient,

bitte fragen Sie uns, wenn Sie die Information nicht verstehen oder mehr zu der beschriebenen Untersuchung wissen möchten.

Die von Ihnen erhobenen Daten unterliegen der ärztlichen Schweigepflicht gemäß §203 StGB und sind den Bedingungen des Bundesdatenschutzes unterworfen.

Ihre Daten sind vor mutwilligem Zugriff geschützt und werden anonymisiert, also ohne Ihren Namen, Geburtsdatum usw. erfasst.

Wir möchten Ihnen für Ihre Mitarbeit danken!

\section{Einverständniserklärung:}

- Ich bin mündlich und schriftlich über die Ziele sowie den Ablauf der Untersuchung informiert worden.

- Ich habe die zur oben genannten Untersuchung schriftliche Patienteninformation erhalten und verstanden. Meine Fragen im Zusammenhang mit der Teilnahme sind mir zufrieden stellend beantwortet worden.

- Ich bin einverstanden, dass die zuständigen Fachleute des Studienauftraggebers, der Behörden und der Ethikkommissionen zu Prüf- und Kontrollzwecken in meine Originaldaten Einsicht nehmen dürfen, jedoch unter strikter Einhaltung der Vertraulichkeit.

- Ich nehme an dieser Studie freiwillig teil. Ich kann jederzeit und ohne Angabe von Gründen meine Zustimmung zur Teilnahme widerrufen; daraus entstehen mir keine Nachteile. Meine Daten werden dann gelöscht. 
Fragebogennr:

Datum:

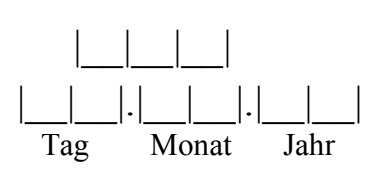

\section{Fragebogen}

Enorale Symptome in der Palliativmedizin in Abhängigkeit vom lokalen mikrobiologischen

Milieu

1. Geburtsdatum: $\left.\left.\right|_{\text {Tag }}\right|_{\text {Monat }}|\cdot|_{\text {Jahr }}||_{\mid} \mid$Geschlecht $\square$ weiblich $\square$ männlich

2. Diagnose:

3. Bisherige Therapie:

$\square$ Chemotherapie, wenn ja welche?:

$\square$ Bestrahlung, wenn ja Region und Dosis?: Region:

Dosis:

Gy

$\square$ Operation, wenn ja welche?:

$\square$ Andere Tumortherapie, wenn ja welche?:

4. Aktuelle Medikation:

5. Art der Ernährung:

$\square$ oral

$\square$ enteral (Sonde)

parenteral

6. Subjektives Empfinden des Patienten:

$\square$ Xersostomie $\square$ Zahnschmerzen $\square$ Mundgeruch $\square$ Unspezifisches Brennen
$\square$ Dysgeusie $\quad \square$ Dysphagie $\quad \square$ Keine Beschwerden
$\square$ Sonstiges $\quad \square$ Patient ist nicht befragbar: Grund:
$\square$ P

7. Wie sehr fühlen Sie sich beeinträchtigt durch Missempfindungen im Mund-/Rachenraum?

gar nicht beeinträchtigt sehr beeinträchtigt

0 100

$\square$ keine Beeinträchtigung $\square$ leichte Beeinträchtigung mittlere Beeinträchtigung starke Beeinträchtigung nicht beurteilbar

8. Motorik des Pateinten

Eigenständige Mundhygiene möglich? $\square$ ja $\square$ nein 
Fragebogennr:

Datum:

9. Art der täglichen Mundhygiene

a. Benutztes Instrument:

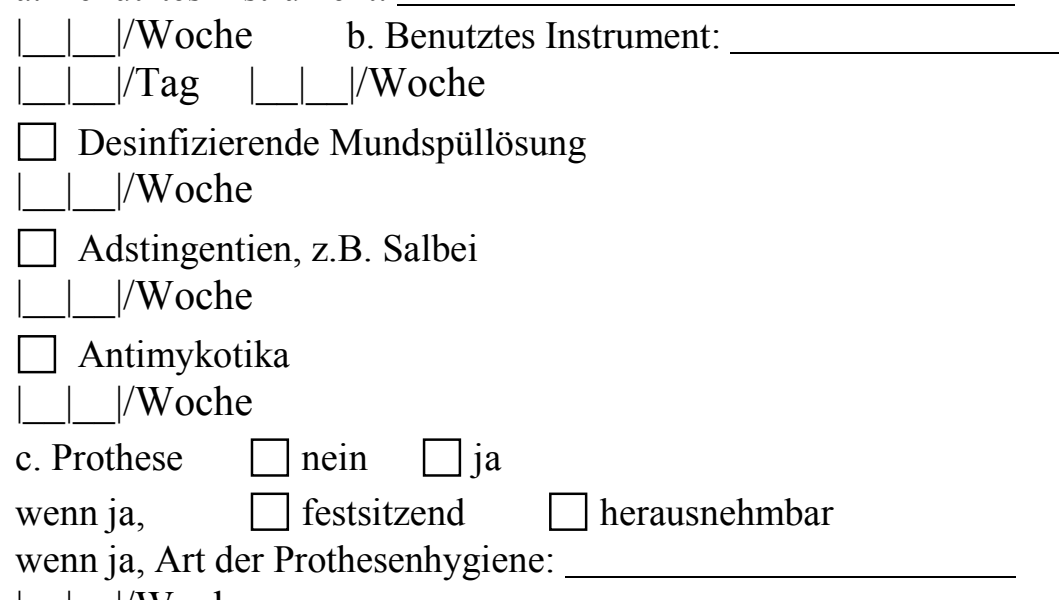

Häufigkeit: |___/Tag Häufigkeit:

Häufigkeit: |___/Tag

Häufigkeit: ____/Tag

Häufigkeit: |___/Tag

Häufigkeit: |___l/Tag |/Woche

10. Anzahl der Zähne:

Oberkiefer:

Unterkiefer:

DMF-T Index:

Lockerungsgrad der Zähne: Oberkiefer:

Unterkiefer: (Durchschnitt)

11. Befund des Zahnersatzes

$\square$ korrekturbedürftig weil

$\square$ normal

12. Gingiva

$\square$ gerötet $\square$ geschwollen $\square$ Blutung auf Sondierung $\square$ Prothesendruckstellen normal

13. Zunge

$\square$ soortypische Belege normal

anderweitige Belege

Schleimhautveränderungen

14. Speichelsekretion
$\square$ reduziert
$\square$ minimal
vermehrt
$\square$ normal

15. Mastikationsfrequenz

$\square$ hoch

mäßig

niedrig

normal

16. Schleimhaut der Mundhöhle

Belege

Ulcus $|-|$ | Anzahl

$\square$ Aphthe |___ Anzahl

Druckstellen

soortypische Beläge

anderweitige

Blutung akut

$\square$ Gingivales Hämatom

normal 
Fragebogennr:

Datum:

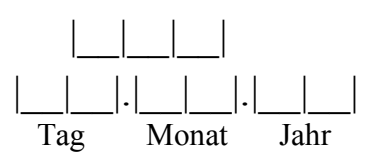

17. Abstrichresultat:

Eingangsnummer (Mikrobiol.):

$\square$ Keime der normalen Mundflora

$\square$ Pilzbesiedelung

$\square$ Bakterielle Fehlbesiedelung $\left|\_L^{\wedge}\right|^{\wedge} L_{\ldots}{ }_{\ldots} \mid \mathrm{ml}$

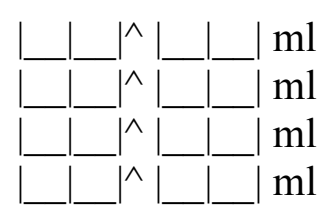

18. Rachenspülwasser

Eingangsnummer (Virologie):

HSV PCR : $\square$ negativ

$\square$ positiv

copies/ $\mu 1$ 
Fragebogennummer |____ _
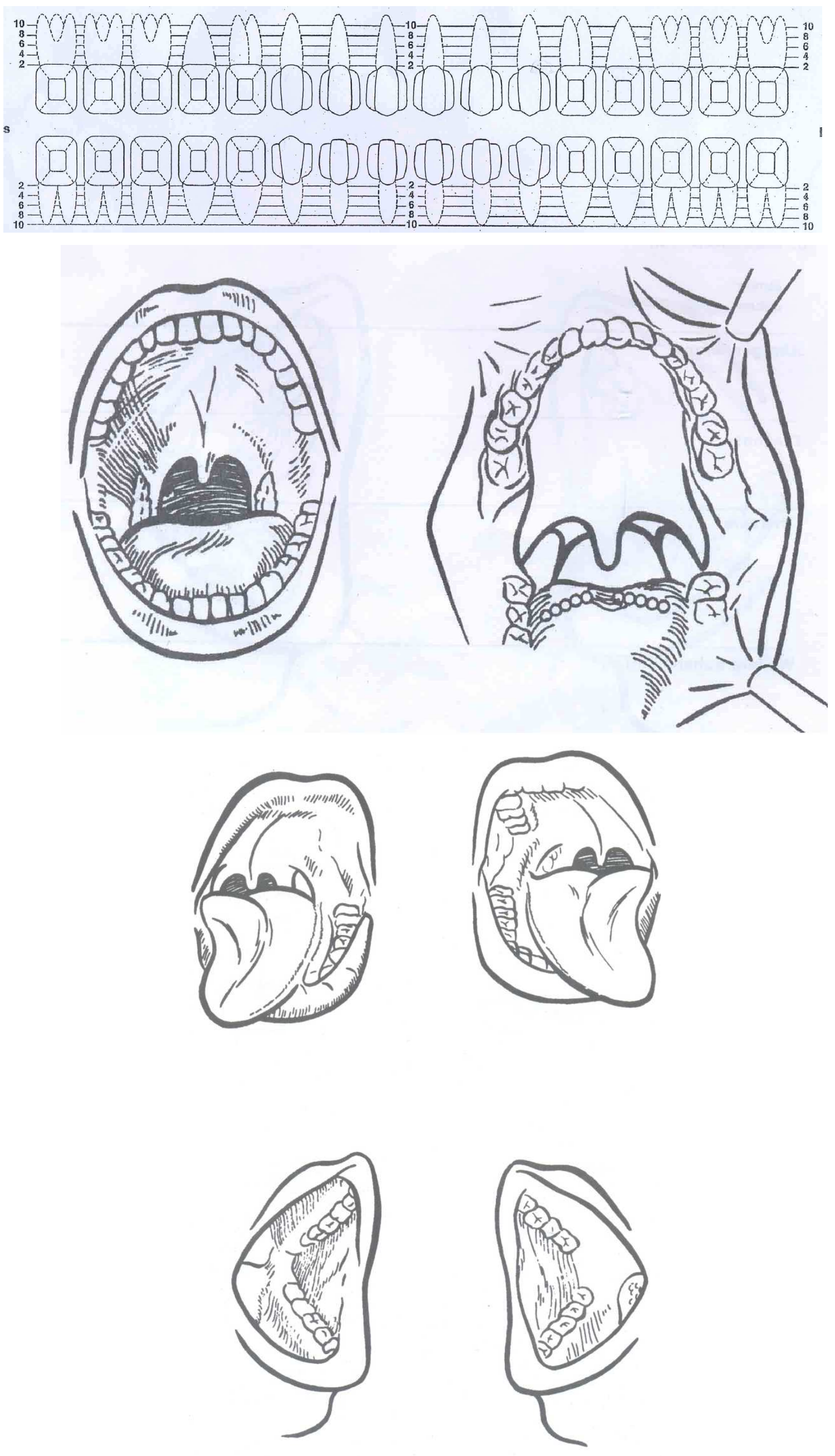


\section{Minimales Dokumentationssystem MIDOS}

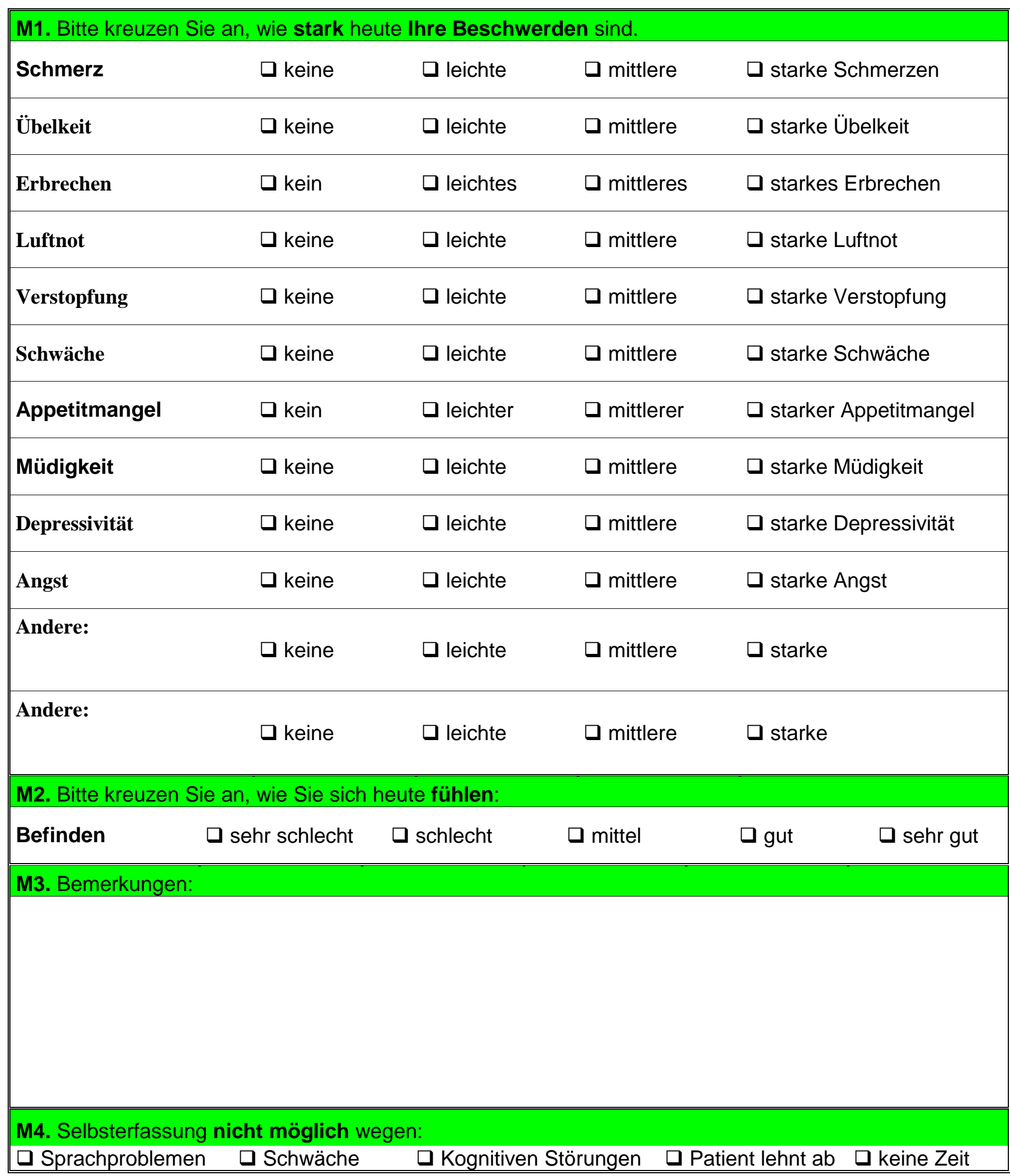


9.2. Ausführliche statistische Auswertung der Korrelationen zu Kapitel 5.15.

\section{Korrelationen von bakteriellen Befunden und klinischen Symptomen}

\begin{tabular}{|c|c|c|c|}
\hline \multirow{2}{*}{ Pilze } & \multicolumn{3}{|c|}{ Korrelation Pilze/Dysgeusie } \\
\cline { 2 - 4 } & $\begin{array}{c}\text { Dysgeusie } \\
\text { JA }\end{array}$ & $\begin{array}{c}\text { Dysgeusie } \\
\text { NEIN }\end{array}$ & Reihe Gesamt \\
\hline JA & 53 & 19 & 72 \\
\hline Spalte $\%$ & $77,94 \%$ & $57,58 \%$ & 29 \\
\hline Reihe \% & $73,61 \%$ & $26,39 \%$ & 14 \\
\hline NEIN & 15 & $42,42 \%$ & 101 \\
\hline Spalte $\%$ & $22,06 \%$ & $48,28 \%$ & \\
\hline Reihe $\%$ & $51,72 \%$ & 33 & \\
\hline Gesamt & 68 & & \\
\hline
\end{tabular}

\begin{tabular}{|c|c|c|c|}
\hline \multirow{2}{*}{ Statistik } & \multicolumn{3}{|l|}{ Statistik: Pilze(2) x Dysgeusie(2) } \\
\cline { 2 - 4 } & Chi-quadrat & $\mathrm{df}$ & $\mathrm{P}$ \\
\hline Pearson Chi-square & 4,501947 & $\mathrm{df}=1$ & $\mathrm{p}=, 03386$ \\
\hline
\end{tabular}

\begin{tabular}{|c|c|c|c|}
\hline \multirow{2}{*}{ Pilze } & \multicolumn{2}{|c|}{ Korrelation Pilze/Xerostomie } \\
\cline { 2 - 4 } & $\begin{array}{c}\text { Xersost } \\
\text { JA }\end{array}$ & $\begin{array}{c}\text { Xersost } \\
\text { NEIN }\end{array}$ & Reihe Gesamt \\
\hline JA & 63 & 9 & 72 \\
\hline Spalte \% & $75,90 \%$ & $50,00 \%$ & 29 \\
\hline Reihe $\%$ & $87,50 \%$ & $12,50 \%$ & \\
\hline NEIN & 20 & 9 & 101 \\
\hline Spalte $\%$ & $24,10 \%$ & $50,00 \%$ & \\
\hline Reihe $\%$ & $68,97 \%$ & $31,03 \%$ & 18 \\
\hline Gesamt & 83 & 18 & \\
\hline
\end{tabular}

\begin{tabular}{|c|c|c|c|}
\hline \multirow{2}{*}{ Statistik } & \multicolumn{3}{|c|}{ Statistik: Pilze(2) $\times$ Xersost(2) (and.bel.z+dysg) } \\
\cline { 2 - 4 } & Chi- quadrat & $\mathrm{df}$ & $\mathrm{P}$ \\
\hline Pearson Chi- quadrat & 4,849112 & $\mathrm{df}=1$ & $\mathrm{p}=, 02766$ \\
\hline
\end{tabular}


Korelationen abweichende bakterielle Besiedelung/Dysgeusie

\begin{tabular}{|c|c|c|c|}
\hline \multirow{2}{*}{ abw. bakt.Besied } & \multicolumn{3}{|c|}{ Beobachtete Häufigkeiten } \\
\cline { 2 - 4 } & $\begin{array}{c}\text { Dysgeusie } \\
\text { JA }\end{array}$ & $\begin{array}{c}\text { Dysgeusie } \\
\text { NEIN }\end{array}$ & Reihe Gesamt \\
\hline JA & 28 & 6 & 34 \\
\hline Spalte $\%$ & $41,18 \%$ & $18,18 \%$ & 67 \\
\hline Reihe $\%$ & $82,35 \%$ & $17,65 \%$ & \\
\hline NEIN & 40 & $81,82 \%$ & 101 \\
\hline Spalte $\%$ & $58,82 \%$ & $40,30 \%$ & \\
\hline Reihe $\%$ & $59,70 \%$ & 33 & \\
\hline Gesamt & 68 & & 27 \\
\hline
\end{tabular}

\begin{tabular}{|c|c|c|c|}
\hline \multirow{2}{*}{ Statistik } & \multicolumn{4}{|c|}{ Statistik: abw. bakt.Besied.(2) x Dysgeusie(2) } \\
\cline { 2 - 4 } & Chi- quadrat & Df & $\mathrm{P}$ \\
\hline Pearson Chi- quadrat & 5,260708 & $\mathrm{df}=1$ & $\mathrm{p}=, 02181$ \\
\hline
\end{tabular}

Korrelation soortypische Beläge auf der Zunge / Xerostomie

\begin{tabular}{|c|c|c|c|}
\hline \multirow{2}{*}{ soort.B.Zunge } & Xersost JA & Xersost NEIN & Reihe Gesamt \\
\cline { 2 - 4 } & 22 & $5,56 \%$ & 23 \\
\hline JA & $26,51 \%$ & $4,35 \%$ & \\
\hline Spalte \% & $95,65 \%$ & 17 & 78 \\
\hline Reihe \% & 61 & $94,44 \%$ & \\
\hline NEIN & $73,49 \%$ & $21,79 \%$ & 101 \\
\hline Spalte \% & $78,21 \%$ & 18 & \\
\hline Reihe $\%$ & 83 & & \\
\hline Gesamt & & & \\
\hline
\end{tabular}

\begin{tabular}{|c|c|c|c|}
\hline \multirow{2}{*}{ Statistik } & \multicolumn{3}{|c|}{ Statistik soort.B.Zunge(2) $\times$ Xersost(2) } \\
\cline { 2 - 4 } & Chi- quadrat & $\mathrm{df}$ & $\mathrm{P}$ \\
\hline Pearson Chi- quadrat & 3,691790 & $\mathrm{df}=1$ & $\mathrm{p}=, 05468$ \\
\hline
\end{tabular}


Korrelation soortypische Beläge auf der Schleimhaut/Xerostomie

\begin{tabular}{|c|c|c|c|}
\hline \multirow{2}{*}{ soort. B. Schleimhaut } & \multicolumn{3}{|c|}{ Beobachtete Häufigkeiten } \\
\cline { 2 - 4 } & $\begin{array}{c}\text { Xersost } \\
\text { JA }\end{array}$ & $\begin{array}{c}\text { Xersost } \\
\text { NEIN }\end{array}$ & Reihe Gesamt \\
\hline JA & 30 & 2 & 32 \\
\hline Spalte \% & $36,14 \%$ & $11,11 \%$ & 69 \\
\hline Reihe \% & $93,75 \%$ & $6,25 \%$ & \\
\hline NEIN & 53 & 16 & \\
\hline Spalte $\%$ & $63,86 \%$ & $88,89 \%$ & 101 \\
\hline Reihe $\%$ & $76,81 \%$ & $23,19 \%$ & \\
\hline Gesamt & 83 & 18 & \\
\hline
\end{tabular}

\begin{tabular}{|c|c|c|c|}
\hline \multirow{2}{*}{ Statistik } & \multicolumn{3}{|c|}{ Statistik: soort. B. Schleimhaut(2) $\times$ Xersost(2) } \\
\cline { 2 - 4 } & Chi- quadrat & Df & $\mathrm{P}$ \\
\hline Pearson Chi- quadrat & 4,282673 & $\mathrm{df}=1$ & $\mathrm{p}=, 03851$ \\
\hline
\end{tabular}

Korrelation anderweitige Beläge auf der Zunge/Xerostomie

\begin{tabular}{|c|c|c|c|}
\hline \multirow{2}{*}{ anderw.B.Zunge } & \multicolumn{3}{|c|}{ Beobachtete Häufigkeiten } \\
\cline { 2 - 4 } & $\begin{array}{c}\text { Xersost } \\
\text { JA }\end{array}$ & $\begin{array}{c}\text { Xersost } \\
\text { NEIN }\end{array}$ & Reihe Gesamt \\
\hline JA & 70 & 11 & 81 \\
\hline Spalte \% & $84,34 \%$ & $61,11 \%$ & \\
\hline Reihe \% & $86,42 \%$ & $13,58 \%$ & 20 \\
\hline NEIN & 13 & 7 & \\
\hline Spalte $\%$ & $15,66 \%$ & $38,89 \%$ & \\
\hline Reihe $\%$ & $65,00 \%$ & $35,00 \%$ & 101 \\
\hline Gesamt & 83 & 18 & \\
\hline
\end{tabular}

\begin{tabular}{|c|c|c|c|}
\hline \multirow{2}{*}{ Statistik } & \multicolumn{4}{|c|}{ Statistik: anderw. B. Zunge(2) $\times$ Xerost.(2) } \\
\cline { 2 - 4 } & Chi- quadrat & $\mathrm{df}$ & $\mathrm{P}$ \\
\hline Pearson Chi- quadrat & 5,024753 & $\mathrm{df}=1$ & $\mathrm{p}=, 02499$ \\
\hline
\end{tabular}


Korrelation anderweitige Beläge Zunge/Dysgeusie

\begin{tabular}{|c|c|c|c|}
\hline \multirow{2}{*}{ anderw. B. Zunge } & \multicolumn{3}{|c|}{ Beobachtete Häufigkeiten } \\
\cline { 2 - 4 } & $\begin{array}{c}\text { Dysgeusie } \\
\text { JA }\end{array}$ & $\begin{array}{c}\text { Dysgeusie } \\
\text { NEIN }\end{array}$ & Reihe Gesamt \\
\hline JA & 58 & 23 & 81 \\
\hline Spalte $\%$ & $85,29 \%$ & $69,70 \%$ & 20 \\
\hline Reihe \% & $71,60 \%$ & $28,40 \%$ & 10 \\
\hline NEIN & 10 & $30,30 \%$ & \\
\hline Spalte \% & $14,71 \%$ & $50,00 \%$ & 101 \\
\hline Reihe $\%$ & $50,00 \%$ & 33 & \\
\hline Gesamt & 68 & & \\
\hline
\end{tabular}

\begin{tabular}{|c|c|c|c|}
\hline \multirow{3}{*}{ Statistik } & \multicolumn{3}{|c|}{ Statistik: anderw.B.Zunge(2) $\times$ Dysgeusie(2) (and.bel.z+dysg) } \\
\cline { 2 - 4 } & Chi- quadrat & Df & $\mathrm{P}$ \\
\hline Pearson Chi- quadrat & 3,403452 & $\mathrm{df}=1$ & $\mathrm{p}=, 06506$ \\
\hline
\end{tabular}

\section{Korrelation anderweitige Beläge auf der Schleimhaut/Xerostomie}

\begin{tabular}{|c|c|c|c|}
\hline \multirow{2}{*}{ anderweit. B. Schleimhaut } & \multicolumn{3}{|c|}{ Beobachtete Häufigkeiten } \\
\cline { 2 - 4 } & $\begin{array}{c}\text { Xersost } \\
\text { JA }\end{array}$ & $\begin{array}{c}\text { Xersost } \\
\text { NEIN }\end{array}$ & Reihe Gesamt \\
\hline JA & 57 & 6 & 63 \\
\hline Spalte \% & $68,67 \%$ & $33,33 \%$ & \\
\hline Reihe \% & $90,48 \%$ & $9,52 \%$ & 38 \\
\hline NEIN & 26 & 12 & \\
\hline Spalte \% & $31,33 \%$ & $66,67 \%$ & 101 \\
\hline Reihe \% & $68,42 \%$ & $31,58 \%$ & \\
\hline Gesamt & 83 & 18 & \\
\hline
\end{tabular}

\begin{tabular}{|c|c|c|c|}
\hline \multirow{2}{*}{ Statistik } & \multicolumn{3}{|c|}{ Statistik: anderweit. B. Schleimhaut(2) $\times$ Xersost(2) (and.bel.z+dysg) } \\
\cline { 2 - 4 } & Chi- quadrat & $\mathrm{df}$ & $\mathrm{p}$ \\
\hline Pearson Chi- quadrat & 7,872533 & $\mathrm{df}=1$ & $\mathrm{p}=, 00502$ \\
\hline
\end{tabular}


Korrelation Pilze/soortypische Beläge auf der Schleimhaut

\begin{tabular}{|c|c|c|c|}
\hline \multirow{2}{*}{ Pilze } & \multicolumn{3}{|c|}{ Beobachtete Häufigkeiten } \\
\cline { 2 - 4 } & $\begin{array}{c}\text { Soort. B. Schleimhaut } \\
\text { JA }\end{array}$ & $\begin{array}{c}\text { soort. B. Schleimhaut } \\
\text { NEIN }\end{array}$ & Reihe Gesamt \\
\hline JA & 28 & 44 & 72 \\
\hline Spalte $\%$ & $87,50 \%$ & $63,77 \%$ & 29 \\
\hline Reihe $\%$ & $38,89 \%$ & $61,11 \%$ & \\
\hline NEIN & 4 & $36,23 \%$ & \\
\hline Spalte $\%$ & $12,50 \%$ & $86,21 \%$ & 101 \\
\hline Reihe $\%$ & $13,79 \%$ & 69 & 25 \\
\hline Gesamt & 32 & & \\
\hline
\end{tabular}

\begin{tabular}{|c|c|c|c|}
\hline \multirow{2}{*}{ Statistik } & \multicolumn{3}{|c|}{ Statistik: Pilze(2) $\mathrm{x}$ soort. B. Schleimhaut(2) } \\
\cline { 2 - 4 } & Chi- quadrat & $\mathrm{df}$ & $\mathrm{p}$ \\
\hline Pearson Chi- quadrat & 6,015260 & $\mathrm{df}=1$ & $\mathrm{p}=, 01418$ \\
\hline
\end{tabular}

Korrelation Pilze/soortypische Beläge auf der Zunge

\begin{tabular}{|c|c|c|c|}
\hline \multirow{2}{*}{ Pilze } & \multicolumn{2}{|c|}{ Beobachtete Häufigkeiten } \\
\cline { 2 - 4 } & $\begin{array}{c}\text { soort.B.Zunge } \\
\text { JA }\end{array}$ & $\begin{array}{c}\text { soort.B.Zunge } \\
\text { NEIN }\end{array}$ & Reihe Gesamt \\
\hline JA & 20 & 52 & 72 \\
\hline Spalte $\%$ & $86,96 \%$ & $66,67 \%$ & \\
\hline Reihe \% & $27,78 \%$ & $72,22 \%$ & 29 \\
\hline NEIN & 3 & 26 & \\
\hline Spalte $\%$ & $13,04 \%$ & $33,33 \%$ & 101 \\
\hline Reihe $\%$ & $10,34 \%$ & $89,66 \%$ & 78 \\
\hline Gesamt & 23 & 78 & \\
\hline
\end{tabular}

\begin{tabular}{|c|c|c|c|}
\hline \multirow{2}{*}{ Statistik } & \multicolumn{3}{|c|}{ Statistik: Pilze(2) $\mathrm{x}$ soort.B.Zunge(2) } \\
\cline { 2 - 4 } & Chi- quadrat & $\mathrm{df}$ & $\mathrm{p}$ \\
\hline Pearson Chi- quadrat & 3,572492 & $\mathrm{df}=1$ & $\mathrm{p}=, 05875$ \\
\hline
\end{tabular}


Korrelation Pilze/anderweitige Beläge Schleimhaut

\begin{tabular}{|c|c|c|c|}
\hline \multirow{2}{*}{ Pilze } & \multicolumn{3}{|c|}{ Beobachtete Häufigkeiten } \\
\cline { 2 - 4 } & $\begin{array}{c}\text { anderweit. B. Schleimhaut } \\
\text { JA }\end{array}$ & $\begin{array}{c}\text { anderweit. B. Schleimhaut } \\
\text { NEIN }\end{array}$ & Reihe Gesamt \\
\hline JA & 51 & 21 & 72 \\
\hline Spalte \% & $80,95 \%$ & $55,26 \%$ & 29 \\
\hline Reihe \% & $70,83 \%$ & $29,17 \%$ & \\
\hline NEIN & 12 & $44,74 \%$ & \\
\hline Spalte \% & $19,05 \%$ & $58,62 \%$ & 101 \\
\hline Reihe \% & $41,38 \%$ & 38 & 29 \\
\hline Gesamt & 63 & & \\
\hline
\end{tabular}

\begin{tabular}{|c|c|c|c|}
\hline \multirow{2}{*}{ Statistik } & \multicolumn{4}{|c|}{ Statistik Pilze(2) $\mathrm{x}$ anderweit. B. Schleimhaut(2) } \\
\cline { 2 - 4 } & Chi- quadrat & $\mathrm{df}$ & $\mathrm{p}$ \\
\hline Pearson Chi- quadrat & 7,642175 & $\mathrm{df}=1$ & $\mathrm{p}=, 00570$ \\
\hline
\end{tabular}

Korrelation Pilze/anderweitige Beläge Zunge

\begin{tabular}{|c|c|c|c|}
\hline \multirow[b]{2}{*}{ Pilze } & \multicolumn{3}{|c|}{ Beobachtete Häufigkeiten } \\
\hline & $\begin{array}{c}\text { anderw.B.Zunge } \\
\text { JA } \\
\end{array}$ & $\begin{array}{c}\text { anderw.B.Zunge } \\
\text { NEIN } \\
\end{array}$ & Reihe Gesamt \\
\hline JA & 60 & 12 & 72 \\
\hline Spalte \% & $74,07 \%$ & $60,00 \%$ & \\
\hline Reihe \% & $83,33 \%$ & $16,67 \%$ & \\
\hline NEIN & 21 & 8 & 29 \\
\hline Spalte \% & $25,93 \%$ & $40,00 \%$ & \\
\hline Reihe \% & $72,41 \%$ & $27,59 \%$ & \\
\hline Gesamt & 81 & 20 & 101 \\
\hline
\end{tabular}

\begin{tabular}{|c|c|c|c|}
\hline \multirow{2}{*}{ Statistik } & \multicolumn{3}{|c|}{ Statistik: Pilze(2) $\mathrm{x}$ anderw.B.Zunge(2) } \\
\cline { 2 - 4 } & Chi- quadrat & $\mathrm{df}$ & $\mathrm{p}$ \\
\hline Pearson Chi- quadrat & 1,552192 & $\mathrm{df}=1$ & $\mathrm{p}=, 21281$ \\
\hline
\end{tabular}




\section{Veröffentlichungen}

Teile der Ergebnisse dieser Dissertation wurden als Abstract und wissenschaftlicher Vortrag auf folgendem medizinisch-wissenschaftlichem internationalem Fachkongress vorgestellt:

- Oral symptoms in palliative care and their association with local microbiological and clinical findings. 12th Congress of the European Association for Palliative Care (EAPC), Wien 10.05.09 


\section{Danksagung}

Herrn Prof. Dr. Friedemann Nauck möchte ich recht herzlich für die Überlassung dieses Dissertationsthemas danken. Er öffnete viele Türen und ermöglichte durch sein intensives Engagement und seine menschliche und freundliche Art die Verwirklichung dieser Studie. Dann möchte ich Herrn Prof. Dr. Dr. Helmut Eiffert und seinem Team für die mikrobiologische Auswertung sowie seine inhaltlichen Ergänzungen danken. Des Weiteren möchte ich Herrn Prof. Dr. Dr. Henning Schliephake für seine Unterstützung danken.

Ein besonderer Dank gilt Herrn Dr. med. Bernd Alt-Epping, welcher mir wertvolle Anregungen bei der Planung und praktischen Umsetzung der Studie gegeben hat. Er hatte stets ein offenes Ohr für auftretende Probleme und war geduldig in der Beantwortung sich ergebender Fragen. Durch seine sympathische und sehr kompetente Art leitete er mich durch sehr viele komplizierte Phasen dieser Studie. Dafür möchte ich mich nochmals bedanken.

Einen Dank auch an Frau Bianca Wegener aus der Abteilung Palliativmedizin, für die große Hilfestellung bei der Datenerfassung.

Herrn Dr. Klaus Jung danke ich für die Hilfestellung bei der statistischen Auswertung der Daten. Natürlich gilt auch ein besonderer Dank an die Krankenschwestern und Krankenpfleger der Palliativstation, die mich sehr bei der Durchführung der Studie auf der Station unterstützt haben. 


\section{Lebenslauf}

Mein Name ist Ramtin Kordestani Nejad. Ich wohne in der Stettiner Straße 20, 37085

Göttingen und bin ledig. Am 21.09.1974 wurde ich in Teheran/Iran geboren.

Im Jahre 1980 bin ich im Iran eingeschult worden und besuchte bis zu unserem Umzug nach

Deutschland im Jahre 1987 die Grundschule und einen Teil der Mittelstufe. Von 1987 bis

1989 besuchte ich die Hauptschule Hechingen in Baden Württemberg. Weiterhin besuchte ich in den Jahren 1989 bis 1991 die Person-Realschule in Göttingen/Niedersachsen und beendete meinen schulischen Werdegang auf dem Hainberg-Gymnasium Göttingen mit der Erlangung der Hochschulreife im Jahre 1994.

Im Jahre 1995 begann ich an der Georg-August-Universität zu Göttingen mein Studium der Zahnheilkunde, welches ich im Jahre 2001 mit dem Staatsexamen abschloss. Meine Zeit als Assistenzarzt verbrachte ich in den Jahren 2002-2004 in Bremen und Göttingen. Im Jahre 2005 war ich als Entlastungsassistent mit anschließender Niederlassung in Duderstadt tätig. Seit 2006 bin ich Niedergelassener Zahnarzt in einer Gemeinschaftspraxis in Hann. Münden. 